\title{
Sustaining Human Presence on Mars Using ISRU and a Reusable Lander
}

\author{
Dr. Dale C. Arney ${ }^{1}$, Christopher A. Jones ${ }^{2}$, Jordan J. Klovstad ${ }^{3}$, D.R. Komar ${ }^{4}$, Kevin Earle ${ }^{5}$, Dr. Robert Moses ${ }^{6}$ \\ NASA Langley Research Center, Hampton, VA \\ Hilary R. Shyface ${ }^{7}$ \\ Analytical Mechanics Associates, Hampton, VA 23681
}

\begin{abstract}
This paper presents an analysis of the impact of ISRU, reusability, and automation on sustaining a human presence on Mars, requiring a transition from Earth dependence to Earth independence. The study analyzes the surface and transportation architectures and compared campaigns that revealed the importance of ISRU and reusability. A reusable Mars lander, Hercules, eliminates the need to deliver a new descent and ascent stage with each cargo and crew delivery to Mars, reducing the mass delivered from Earth. As part of an evolvable transportation architecture, this investment is key to enabling continuous human presence on Mars. The extensive use of ISRU reduces the logistics supply chain from Earth in order to support population growth at Mars. Reliable and autonomous systems, in conjunction with robotics, are required to enable ISRU architectures as systems must operate and maintain themselves while the crew is not present. A comparison of Mars campaigns is presented to show the impact of adding these investments and their ability to contribute to sustaining a human presence on Mars.
\end{abstract}

\section{Introduction}

T N May 2014, the Pioneering Space document announced a new philosophy for humans on Mars called pioneering [1]. This philosophy would emphasize building toward a permanent presence of humanity beyond the Earth surface. In that document, exploration and pioneering are distinguished.

\section{"Explorers go with the intent of returning to tell their story and point the way for future forays. Pioneers go with the intent to establish a permanent presence. Pioneering space requires we progress from Earth-dependent to Earth-independent."}

In order to achieve the Earth independence that is required in pioneering, the study team adopted the motto, "Don't Manage Scarcity; Exploit Abundance." In-Situ Resource Utilization (ISRU) involves extracting and utilizing local resources so that they do not need to be delivered from Earth. ISRU is a critical capability for Earth independence, and Mars has several resources in its atmosphere, surface, and even gravitational influence that can be exploited.

The atmosphere can be used to reduce the energy of an entering vehicle. Aerocapture and aeroentry use the atmosphere to decelerate a vehicle without using propellant that would nominally be delivered from Earth, reducing the propellant requirements. Gravity assists, which can be considered gravitational ISRU, at the Moon or Mars also reduce the propellant requirements. Also, the 95 percent carbon dioxide and three percent nitrogen content of the Martian atmosphere can be acquired and utilized to produce useful materials and gases [2].

Water is in the regolith and subsurface of Mars, which permits the production of propellant (methane, hydrogen, other hydrocarbons, and oxygen) and crew consumables (water, oxygen, nitrogen, and food). When combined with

\footnotetext{
${ }^{1}$ Aerospace Engineer, Space Mission Analysis Branch, MS 462, AIAA Member.

${ }^{2}$ Aerospace Engineer, Space Mission Analysis Branch, MS 462, AIAA Member.

${ }^{3}$ Aerospace Engineer, Space Mission Analysis Branch, MS 462.

${ }^{4}$ Aerospace Engineer, Vehicle Analysis Branch, MS 451, AIAA Senior Member.

${ }^{5}$ Aerospace Engineer, Space Mission Analysis Branch, MS 462, AIAA Member.

${ }^{6}$ Aerospace Engineer, Atmospheric Flight and Entry Systems Branch, MS 489, AIAA Associate Fellow.

${ }^{7}$ Project Engineer, 21 Enterprise Parkway, Suite 300, AIAA Member.
} 
the carbon dioxide, plastics could be produced and manufactured in-situ to create spares and other necessary items, further reducing the dependency on Earth-supplied logistics. The concentration of available water in the regolith is from approximately three percent by mass near the equator to greater than 40 percent above 60 degrees latitude [3]. In some specific locations, the concentration is potentially above 60 percent. Beyond the water, bulk regolith can be used to provide material for radiation protection, thermal management, civil engineering, and even production of higher quality building materials (e.g. bricks).

Langley technical leadership recognized the potential for ISRU to enable sustained human pioneering of Mars. In response, they held a day-long blue sky meeting in July 2014 to kick off an architecture study to analyze the potential benefit of ISRU, along with automation and reusability, to enable a sustained human presence on the Mars surface. The results of this study would inform NASA's human Mars exploration conversations. The study has three objectives to support that goal:

- Trade system and technology needs for a sustained human presence on the Mars surface.

- Explore options for an evolvable Earth-Mars transportation architecture that leverages automation and ISRU to reduce costs and risks.

- Integrate surface and transportation concepts into a phased build-up showing how NASA will transition from current systems and technologies to a sustained human presence on the Mars surface.

\section{Background}

The most recent reference mission developed by NASA for crewed travel to Mars is the Design Reference Architecture 5.0, or DRA 5 [4]. The mission consists of two phases: a pre-deployment phase during which two cargo Mars Transfer Vehicles (MTVs) deliver payload to Mars from Low Earth Orbit (LEO), and a crewed phase during which another MTV delivers the crew to Mars and returns them to Earth after the crew's surface mission. These MTVs are delivered to LEO on multiple heavy-lift launches; the concept of operations called for eleven launches of the Ares $\mathrm{V}$ cargo launch vehicle, and one launch of the Ares I crew launch vehicle, to deliver all the Initial Mass in LEO (IMLEO). In total, the architecture required approximately $850 \mathrm{t}$ of IMLEO to enable a crew of six to visit Mars for 500 days; any future visits would have required launching another full-up package.

One class of technologies proposed for reducing the mass of Mars missions, especially those that would return to a single site, is ISRU [2-6]. Studies have shown that replacing the ascent propellant for departing the surface of Mars with a system to produce that propellant locally results in net mass savings, with as much as a $60 \%$ reduction in the mass landed on Mars [6]. From calculations of the "gear ratios" for landing mass on Mars, each kilogram saved on the surface results in a reduction of between 10.5 and 17 kilograms in LEO [3,5].

The most influential crewed Mars architecture outside of NASA's designs is Robert Zubrin's Mars Direct. Portree, in his history of crewed Mars mission planning, says that "[s]ince 1992, NASA has based most of its Mars plans on the Mars Direct concept developed in 1990 by Martin Marietta" [7]. This architecture, released in the aftermath of NASA's 90-Day Study [8], proposed doing a minimalist crewed mission with just two heavy lift launches from Earth. Unlike subsequent NASA architectures, which split the Mars ascent and Earth return capabilities across distinct vehicles, Mars Direct combined both functions in a single vehicle. This Earth Return Vehicle (ERV) would use $96 \mathrm{t}$ of oxygen and methane propellant derived from $6 \mathrm{t}$ of hydrogen brought from Earth to perform the $6.8 \mathrm{~km} / \mathrm{s}$ of $\Delta \mathrm{V}$ required to return to Earth from the surface of Mars. Zubrin assumes that the ISRU system to produce this propellant is $0.5 \mathrm{t}$, along with a $3.5 \mathrm{t}$ nuclear reactor. Although the NASA architectures that followed did not use ISRU to the same degree as Mars Direct, nor did they make sizing assumptions as optimistic as Zubrin's, they did incorporate (sometimes partial) propellant production in most of the architectures studied from the 1990s onward [3].

The NASA mission concept referred to as Design Reference Mission 1, or "DRM-1" (Human Exploration of Mars: The Reference Mission of the NASA Mars Exploration Study Team) incorporated ISRU for both propellant production (methane and oxygen for the ascent vehicle) and crew consumable production (water, oxygen, and a nitrogen/argon buffer gas mix). The in-situ propellant production was required for the architecture, while the consumables were a reserve cache supplementing those brought from Earth. Propellant production relied on acquiring atmospheric carbon dioxide and reacting it with hydrogen brought from Earth; carbon dioxide electrolysis was used to provide the additional oxygen needed for an ideal mixture ratio. The system was sized to produce $20 \mathrm{t}$ of oxygen and $6 \mathrm{t}$ of methane for the ascent vehicle, along with $23 \mathrm{t}$ of water, $4.5 \mathrm{t}$ of breathable oxygen, and $3.9 \mathrm{t}$ of buffer gas, from $4.5 \mathrm{t}$ of hydrogen; this sizing did not include the systems for acquiring the atmosphere, storing the hydrogen, or liquefying and storing the cryogenic fluids [9].

In the follow-on study referred to as "DRM-3" (Reference Mission Version 3.0: Addendum to the Human Exploration of Mars: The Reference Mission of the NASA Mars Exploration Study Team), the same ISRU systems as proposed in DRM-1 were used, with two changes. First, the crew consumables production moved from a supplemental 
role to a critical role; this allowed for the elimination of other payloads that were driving several changes in the architecture. Second, the propellant requirement increased from $26 \mathrm{t}$ to $39 \mathrm{t}$, with a corresponding increase in required hydrogen from $4.5 \mathrm{t}$ to $5.5 \mathrm{t}$. The authors claim that the ISRU plant mass decreased from $4.8 \mathrm{t}$ to $3.9 \mathrm{t}$. Again, this does not appear to include systems for acquiring the atmosphere, storing the hydrogen, or liquefying and storing the cryogenic products [10].

Although the Exploration Systems Architecture Study (ESAS) focused on plans for a lunar mission, it did sketch out a crewed Mars mission (without stating masses). There is no use of Mars ISRU in the proposed architecture; instead, all of the mass needed to sustain the crew at the surface, as well as the ascent vehicle propellant, is delivered from Earth [11]. Follow-on work to revise the architecture during the Constellation program also excluded ISRU [3].

After surveying the previous Mars architectures, Rapp aggregated several common assumptions and developed a representative architecture. He calculated that for launching a $5 \mathrm{t}$ payload from the surface of Mars to an undefined elliptical orbit for Earth return, $47 \mathrm{t}$ of propellant would be needed. His assumption for the ISRU system to produce that propellant (not including power, which he accounts for in a separate $30 \mathrm{t}$ cargo landing) is $6 \mathrm{t}$ [3].

In DRA 5, ISRU was used to supply the oxygen for the ascent vehicle as well as water, oxygen, and buffer gases to make up for loses during EVA operations, while the ascent vehicle's methane, along with most of the crew consumables, were sent from Earth. This system, with an estimated mass of $1 \mathrm{t}$, and $400 \mathrm{~kg}$ of hydrogen would produce $25 \mathrm{t}$ of oxygen for the ascent vehicle, $2 \mathrm{t}$ of oxygen for the crew, and $133 \mathrm{~kg}$ of nitrogen/argon buffer gas, along with an unspecified amount of water [4]. The system was estimated to use between $24 \mathrm{kWe}$ [4] and $30 \mathrm{kWe}$ [12]. Additional trades of other ISRU options were evaluated, but dismissed for complexity or technological reasons.

In May 2014, NASA released Pioneering Space, which announced a new philosophy to motivate a sustained human presence on Mars. While previous mission studies have focused on exploration of Mars, none have performed a high level evaluation of the ISRU systems and other technologies at the architectural and campaign level to enable a sustained human presence on Mars. Pioneering and exploration have different development and implementation needs that must be considered concurrently with the entire campaign of Mars missions.

\section{Path to Pioneering Mars}

Pioneering Mars requires a concerted effort over multiple decades. Four phases were defined to describe the path from current capabilities to sustaining a human presence on Mars. These four phases are described in Figure 1. The initial phase, Prepare, advances the technologies and builds systems to enable sustainable human exploration. This phase would also contain missions to local bodies (e.g. cis-lunar space) to develop, prove, and sustain needed capabilities. The Found phase would begin with the first human landing on Mars. This initial human surface presence would emplace the necessary hardware and infrastructure to support short-term human presence on Mars. The Expand phase increases the infrastructure on Mars to support a larger population and longer stays. Utilizing the infrastructure initially emplaced during the Found phase as well as additional capability to utilize in-situ resources, crew size can increase while reliance on Earth resources can decrease. Finally, the Sustain phase maintains a large human presence on Mars through extensive use of in-situ resources, automation, and reusability to explore and settle the planet.

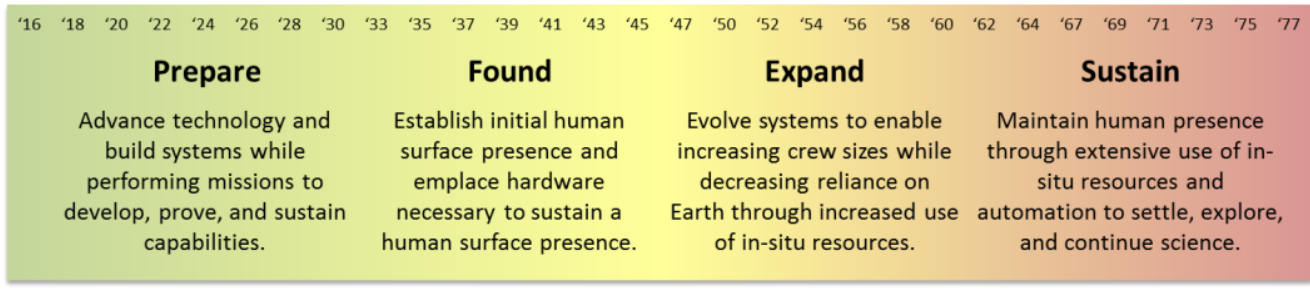

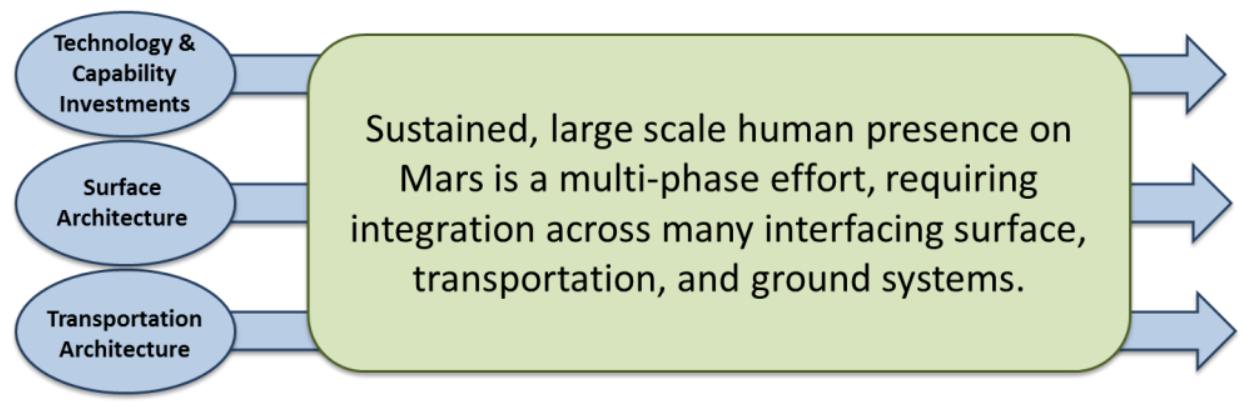

Figure 1: Four Phase Approach for Sustained Human Presence on Mars 
In order to enable the Sustain phase, decisions must be made during the Prepare and Found phases to place the exploration policy on this path. Across all four of these phases, technology and capability investments, surface architecture, and transportation architecture must be considered in any and all decisions. Sustained, large-scale human presence on Mars cannot be added after the fact; it requires integration across many interfacing surface, transportation, and ground systems that must be started and developed during the early phases to support the later ones.

This paper presents the surface and transportation architectures to support pioneering Mars. Three campaigns are analyzed to determine the impact that ISRU and reusability have on sustaining human presence. Automation is prevalent through all Mars architectures due to the need for elements to operate without crew being present. The evolvable transportation architecture uses $\mathrm{LOX} / \mathrm{CH}_{4}$ propulsive stages to transfer cargo and crew between Earth and Mars and a Single-Stage Reusable Lander (SSRL) called Hercules to provide efficient access to the Mars surface. This transportation architecture can evolve into a reusable in-space architecture with large Mars surface-to-orbit capability by adding a fly-back booster called Pegasus. The surface architecture varies based on the campaign but utilizes Mars resources to the greatest extent practicable. Water in the regolith and carbon dioxide in the atmosphere provide key resources to make propellant, potable water, consumables, and even manufactured items like plastics and spare parts.

\section{Surface Architecture}

The principle elements of the surface architecture are the propellant ISRU system, the surface power system, the habitation system, and the other ISRU systems. Each of the elements is described below.

\section{A. Propellant ISRU}

Previous studies have identified methane and oxygen, produced from Martian carbon dioxide and a source of hydrogen, as a potential propellant that can be manufactured on Mars, leading to significant reductions in landed mass on Mars [2]. The Sabatier process converts carbon dioxide and hydrogen to methane and water; the water can then be electrolyzed into oxygen, stored for eventual use, and hydrogen, recycled back to the Sabatier reactor. It is assumed in this study that the ISRU plant is located near a significant quantity of high concentration water $(\sim 40 \%)$ in the regolith; this water provides the initial source of hydrogen.

The system used here consists of several components. A sorbent bed that collects carbon dioxide during the nighttime and discharges it during the day produces a supply for the Sabatier reactor. A series of excavators, similar to those described in DRA 5 [2], collect regolith and bring it to a water processing plant, which extracts the water and passes it to the electrolyzer. The Sabatier reactor uses the incoming streams of carbon dioxide and hydrogen to produce methane and water. The methane is liquefied and stored aboard the reusable Mars surface-to-orbit system, while the water flows into the electrolyzer. The electrolyzer uses a proton exchange membrane to separate hydrogen and oxygen from the incoming water streams. The oxygen is liquefied and stored either aboard the Mars surface-to-orbit system, or in the habitat oxygen supply tanks.

As presented in Section V.C of this paper, the Mars surface-to-orbit vehicle requires $74 \mathrm{t}$ of methane and oxygen propellant, at an O/F ratio of 3.5, for each roundtrip to Low Mars Orbit (LMO) and back it makes. In addition, the plastics manufacture system requires $2.2 \mathrm{t}$ of methane as an annual input, and the crew of four requires $2.5 \mathrm{t}$ of oxygen and $10 \mathrm{t}$ of water annually. The combined system for producing the propellant and additional methane, oxygen, and water is $5.2 \mathrm{t}$ and requires $106 \mathrm{kWe}$. For the Extensive ISRU campaign, which has the Mars surface-to-orbit vehicle fly twice annually, a second copy of the ISRU system is eventually delivered.

\section{B. Surface Power}

Due to the hundreds of kilowatts required for the ISRU and other systems on the surface of Mars, nuclear power was assumed as the baseline technology for providing electrical power in this study; this follows the trade studies discussed in DRA 5.0 [2]. The surface power system consists of the nuclear reactor itself, power conversion system, power management and distribution system, and radiators. In his discussion of nuclear power systems, Mason shows that as the power requirement for a power system rises, the specific mass, measured in $\mathrm{kg} / \mathrm{kWe}$, follows an exponential decrease [13]. From an exponential regression of previous estimates of integrated nuclear power system masses and power levels, it was determined that a $110 \mathrm{kWe}$ system capable of operating the propellant ISRU system required at the beginning of the campaign would weigh $12.1 \mathrm{t}$; this estimate may prove conservative depending upon progress in designing space-rated nuclear power systems.

The first Mars surface payload in the Light ISRU and Extensive ISRU campaigns consists of the propellant ISRU system, surface power system, cabling, surface mobility to transport the reactor a safe distance from the landing site, and startup power. The surface mobility system includes a $1.2 \mathrm{t}$ payload offloading system and unpressurized rover. The startup power system, a $0.5 \mathrm{t}$ system that provides $1 \mathrm{kWe}$, facilitates the initial offloading and emplacement of 
the nuclear surface power system, after which the nuclear system takes over power production. As additional payloads are landed and additional power is needed (for example, for the habitats), two additional power systems are landed for the Light ISRU campaign, while three additional systems are delivered for the Extensive ISRU campaign, enabling the operation of a second propellant ISRU system.

\section{Habitation}

Two types of habitats are used by the crews on the surface of Mars: a monolithic habitat for initial crews, and pressurized logistics carriers modified to augment habitable volume. The monolithic habitation module will be delivered as a payload on either a disposable lander or the SSRL. The dry mass of this habitat is $20 \mathrm{t}$ and requires 30 $\mathrm{kWe}$ of power, while providing $100 \mathrm{~m}^{3}$ of habitable volume. Pressurized logistics carriers will be required to deliver many of the initial consumables and equipment that outfits the habitat. Each pressurized logistics carrier delivers 5.5 $\mathrm{t}$ of cargo, is $3.2 \mathrm{t}$ of dry mass, requires $1 \mathrm{kWe}$ of power, is $3.5 \mathrm{~m}$ in diameter, and is $8.2 \mathrm{~m}$ long. This logistics in these carriers include food, spare parts, and other consumables.

In the Extensive ISRU campaign, two of the monolithic habitat modules are eventually delivered, provisioned with a combination of ISRU-generated products and consumables delivered from Earth. This capability can support up to eight crew on the surface of Mars at one time. To further expand the habitable volume for greater crew size, it is anticipated that the pressurized logistics carriers could also be used as habitable volume. In conjunction with outfitting equipment delivered in subsequent flights from Earth and the expanded ISRU capabilities in later missions, this would enable expansion of the space available for additional crew to live and work.

\section{Other ISRU}

As the initial capabilities of the Extensive ISRU campaign are deployed and operated, there exist opportunities to further reduce the dependency on supply from Earth. In their Mars colonization proposal, Powell et al. indicate that as much as 30\% of the food mass transported from Earth could be replaced by algae and yeast grown on Mars [14]. Based on calculations derived from their study, a food production system of $2 \mathrm{t}$ and requiring $27 \mathrm{kWe}$ could produce $1 \mathrm{t}$ of algae food per year. Three of these systems would be used by the full crew complement of 20.

Plastics (polyethylene) can be produced from methane manufactured on Mars; these plastics can then be used with advanced manufacturing processes (e.g. 3-D printing) to produce space parts on demand. Based on the work of Carranza et al. [15], a system less than $1 \mathrm{t}$ and requiring $5 \mathrm{kWe}$ of power could produce $2 \mathrm{t}$ of plastic feedstock from $2.6 \mathrm{t}$ of methane per year. Six of these systems would be used by the full crew complement of 20 .

\section{Transportation Architecture}

\section{A. Overview}

To support the goals of ISRU, automation, and reusability, the transportation concept is an evolvable transportation architecture, both in space and from the Martian surface to orbit. Capabilities and technology investments necessary for the evolved systems impose constraints on the initial systems, but these investments are necessary to support a sustained human presence on Mars. This study focuses on the development and deployment of the initial capabilities with the emphasis on building up a sustained human presence on Mars.

The in-space architecture uses a disposable, liquid oxygen/liquid methane $\left(\mathrm{LOX} / \mathrm{CH}_{4}\right)$ propulsion system that has the ability expand into a reusable system that uses ISRU-produced propellants. The initial in-space transportation architecture consists of two LOX/CH 4 vehicles: one stage to perform the Trans-Mars Injection (TMI) and Mars Orbit Insertion (MOI) burns, and another to perform the Trans-Earth Injection (TEI) burn. In the evolved capability, the inspace propulsion system could function as the both the TMI/MOI stage as well as the TEI stage by refueling in LMO if ISRU-produced propellant is available.

The SSRL can evolve from an initial Single Stage to Orbit (SSTO) system to a more capable Two-Stage to Orbit (TSTO) system. The initial SSRL, called Hercules, uses ISRU-produced $\mathrm{LOX} / \mathrm{CH}_{4}$ propellant to deliver $20 \mathrm{t}$ from LMO to the Martian surface or crew to and from orbit. The TSTO configuration uses Hercules as the second stage and adds a $\mathrm{LOX} / \mathrm{CH}_{4}$ fly-back booster called Pegasus for the first stage. The evolved TSTO enables large payload delivery to LMO that would support using Mars ISRU-produced propellant in orbit.

Figure 2 and Figure 3 describe the concept of operations for the initial and recurring missions. Systems are assumed to be launched atop a $130 \mathrm{t}$ Space Launch System (SLS), which has a flight rate of two flights per year with the ability to surge to three occasionally. Systems are aggregated in Lunar Distance Retrograde Orbit (LDRO) before departing for Mars. The assumed delivery capability for the SLS is listed in Table 1, where the fast transfer captures directly into LDRO and the slow transfer uses a Lunar Gravity Assist (LGA) and Ballistic Lunar Transfer (BLT) to capture into LDRO. Once all elements are aggregated in LDRO, the stack of vehicles performs a LGA to insert into a Lunar 
Distant High Earth Orbit (LD-HEO). The TMI burn is performed at the periapsis of this orbit to take advantage of the Oberth effect. The total $\Delta \mathrm{V}$ of this maneuver is listed in Table 1 as the Earth departure $\Delta \mathrm{V}$. Upon arrival at Mars, the stack is captured into LMO at a circular altitude of $400 \mathrm{~km}$ using the MOI maneuver. The typical configuration of these stacks of vehicles contains two stages that combine to perform the TMI and MOI burns, which can place $65 \mathrm{t}$ into LMO in a single trip.

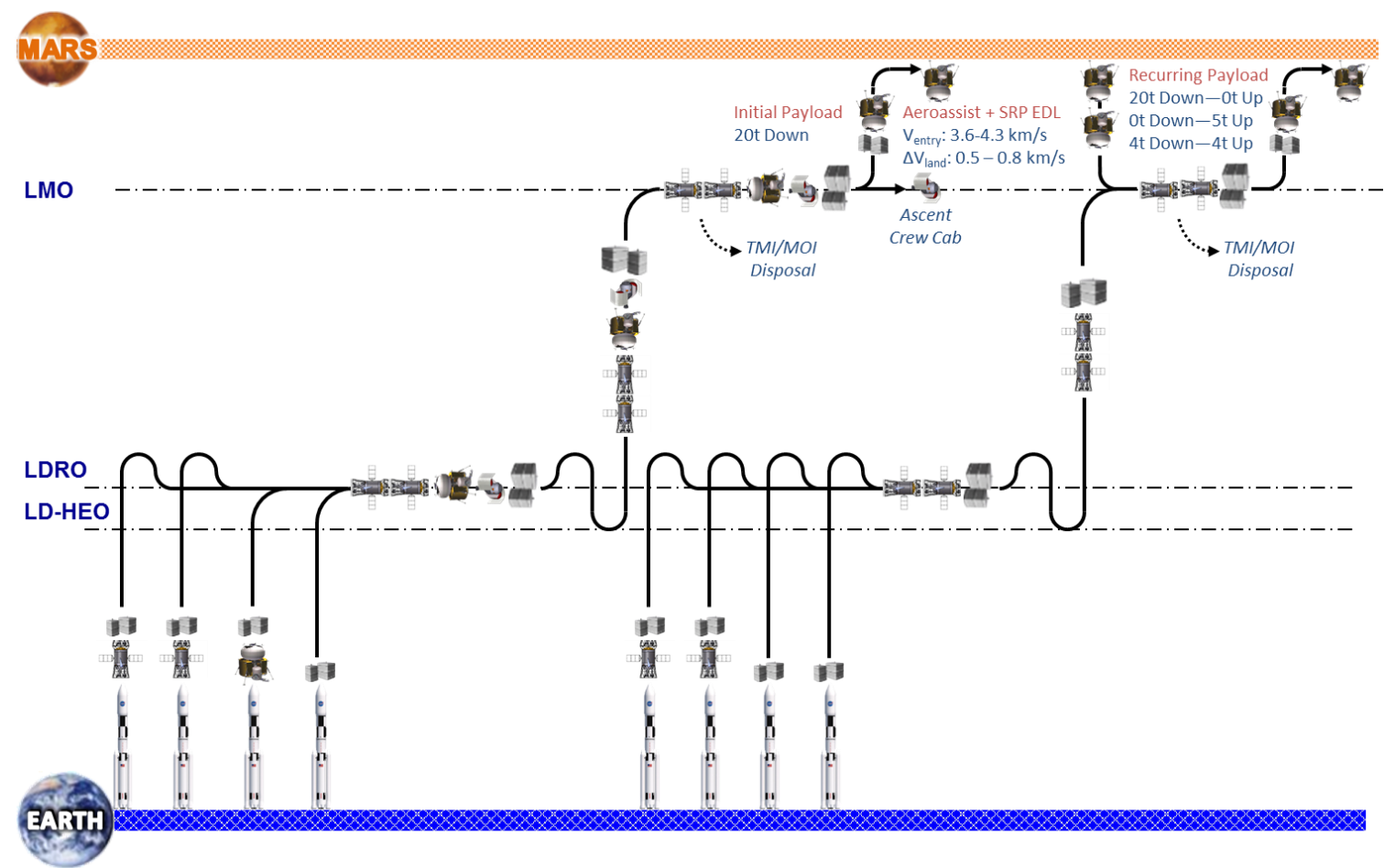

Figure 2: Cargo Mission Concepts of Operations

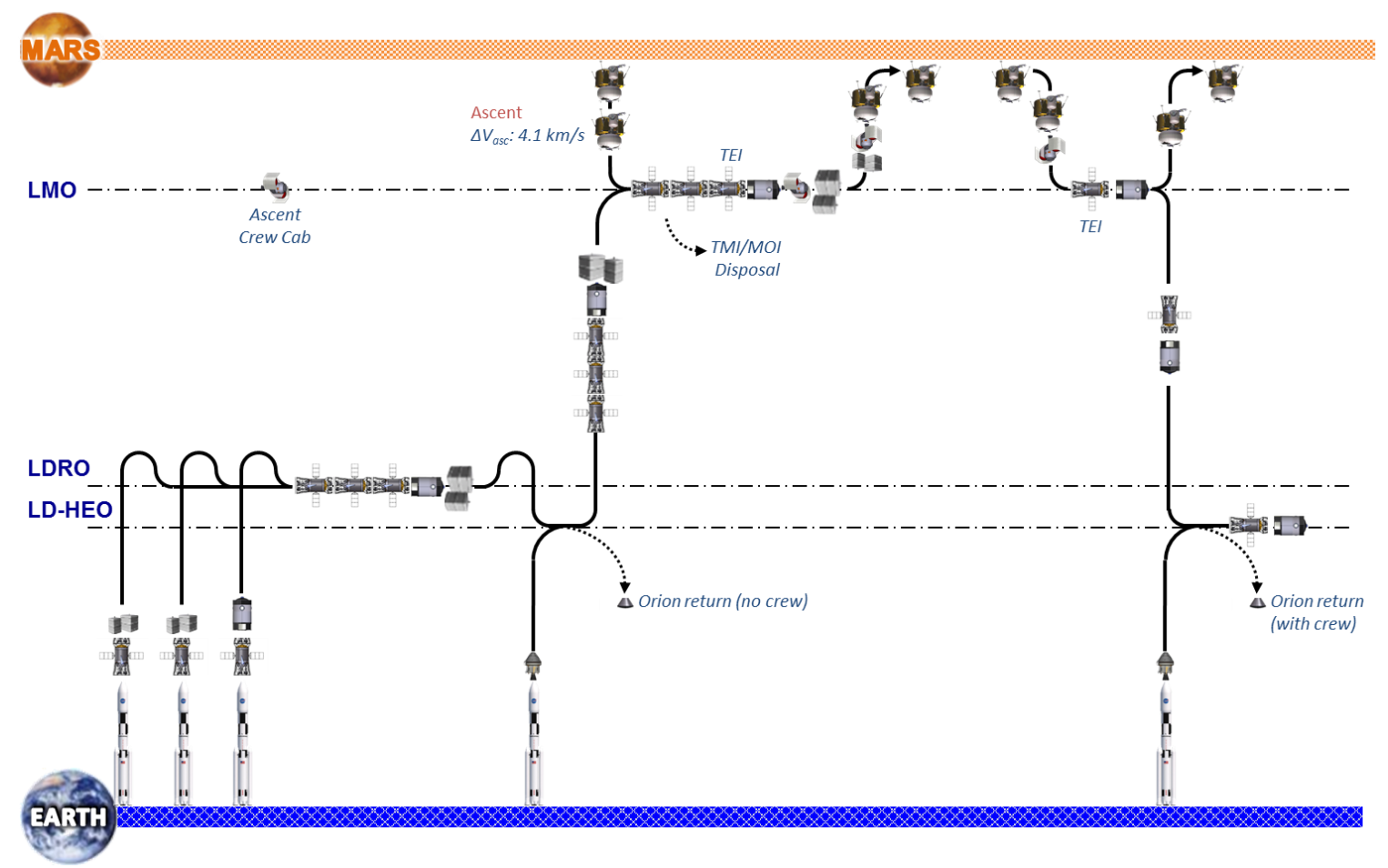

Figure 3: Crew Mission Concept of Operations

American Institute of Aeronautics and Astronautics 
Table 1: Transportation Assumptions

\begin{tabular}{|c|c|}
\hline Parameter & Value \\
\hline \multicolumn{2}{|l|}{ SLS Capability to LDRO } \\
\hline Slow Transfer & $40 \mathrm{t}$ \\
\hline Fast Transfer & $50 \mathrm{t}$ \\
\hline Earth (LDRO) Departure $\Delta \mathrm{V}$ & $578 \mathrm{~m} / \mathrm{s}$ \\
\hline Mars (LMO) Arrival $\Delta \mathrm{V}$ & $2,019 \mathrm{~m} / \mathrm{s}$ \\
\hline Mars (LMO) Departure $\Delta \mathrm{V}$ & $2,215 \mathrm{~m} / \mathrm{s}$ \\
\hline Earth (LDRO) Arrival $\Delta \mathrm{V}$ & $482 \mathrm{~m} / \mathrm{s}$ \\
\hline
\end{tabular}

In the first flight, the Hercules SSRL is delivered to LMO with an ISRU plant, a power plant, and the crew ascent/descent cabin. The crew ascent/descent cabin remains in LMO until the first crew arrives. Hercules enters and lands at the site where the base will be established and deploys the ISRU and power plants. These plants produce $\mathrm{LOX} / \mathrm{CH}_{4}$ propellant for the Hercules lander to ascend and return with more payloads on subsequent missions.

In subsequent cargo flights, the cargo is delivered to LMO in a similar fashion to the first flight. Hercules, which is fully fueled with the ISRU plant on the surface ascends and rendezvouses with the delivered cargo. Hercules then descends using aeroassist and supersonic retro-propulsion to deliver the cargo to the base.

The crew flights contains additional elements to support the crew and enable their eventual return to Earth after their surface stay has ended. The transit habitat houses the crew during their interplanetary journey while the TEI stage performs the burns to return the crew from LMO back to the LDRO. The $\Delta \mathrm{V}$ for this maneuver is listed in Table 1 as the Mars departure $\Delta \mathrm{V}$. These two vehicles, along with necessary logistics from Earth and the crew itself, are transported from LDRO to LMO with two TMI/MOI stages similar to the cargo flights. The crew descends to the surface in the crew ascent/descent cabin that was loitering in LMO atop Hercules, which ascended with ISRUproduced propellant just before crew arrival. The transit habitat and TEI stage remains in LMO during the surface stay. After the surface stay, the crew ascends in the ascent/descent cabin aboard Hercules to the transit habitat and TEI stage, which return the crew to LDRO. The crew ascent/descent cabin remains in LMO for the next crew and the Hercules returns to the Mars surface without crew or cargo. After arrival in LDRO, the crew return to Earth via a crew capsule delivered on an SLS before the crew arrived.

\section{B. In-Space Transportation}

The in-space transportation architecture was developed using simple Propellant Mass Fraction (PMF) sizing. The TMI/MOI and TEI stages use the performance requirements in Table 1 and use $\mathrm{LOX} / \mathrm{CH}_{4}$ propellant to leverage the potential for refueling with ISRU-produced propellant. The assumed specific impulse (Isp) is 360 seconds and assumed PMF is 0.9, and the resulting systems are presented in Figure 4. This simplified sizing model was used for the in-space architecture because the focus was placed on the SSRL analysis, as it is the key to accomplishing the goal of sustained human presence on Mars. The in-space transportation architecture uses reasonable assumptions for achievable $\mathrm{LOX} / \mathrm{CH}_{4}$ propulsion stages in the near future. 


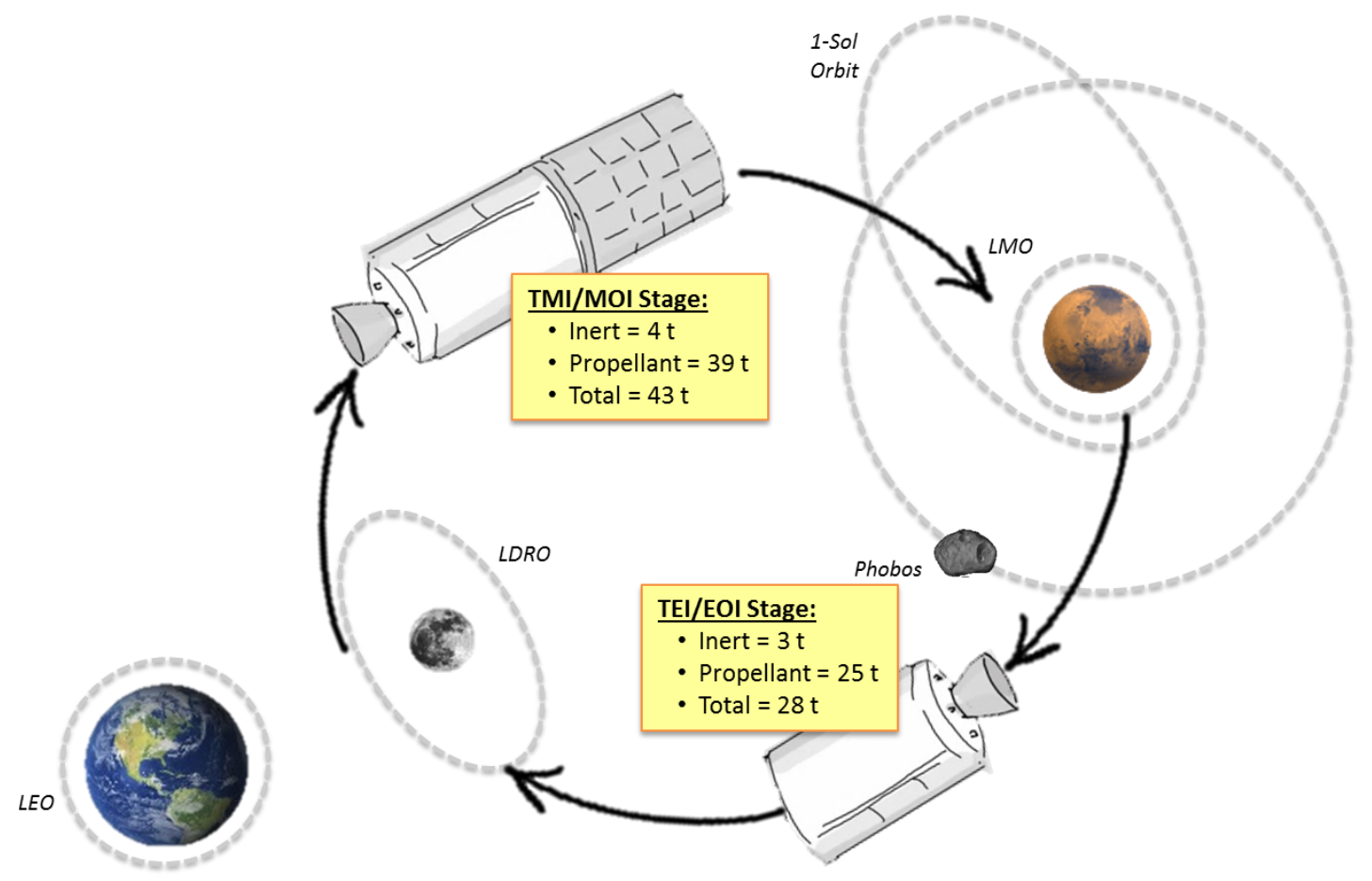

Figure 4: Initial In-Space Transportation Architecture

To understand the impact of the PMF assumption on the feasibility of the overall in-space architecture, a sensitivity analysis was performed. The PMF was varied from the baseline of 0.9 to determine the lowest PMF system that could still launch on a single SLS to LDRO. The results of this analysis are presented in Figure 5, showing the total mass of the TMI/MOI system (inert and propellant) versus the assumed PMF. The figure reveals a minimum PMF for both systems (TMI/MOI and TEI) of 0.86 to fit on a single SLS. Systems with a PMF above 0.86 are very common on commercially available and existing vehicles [16].

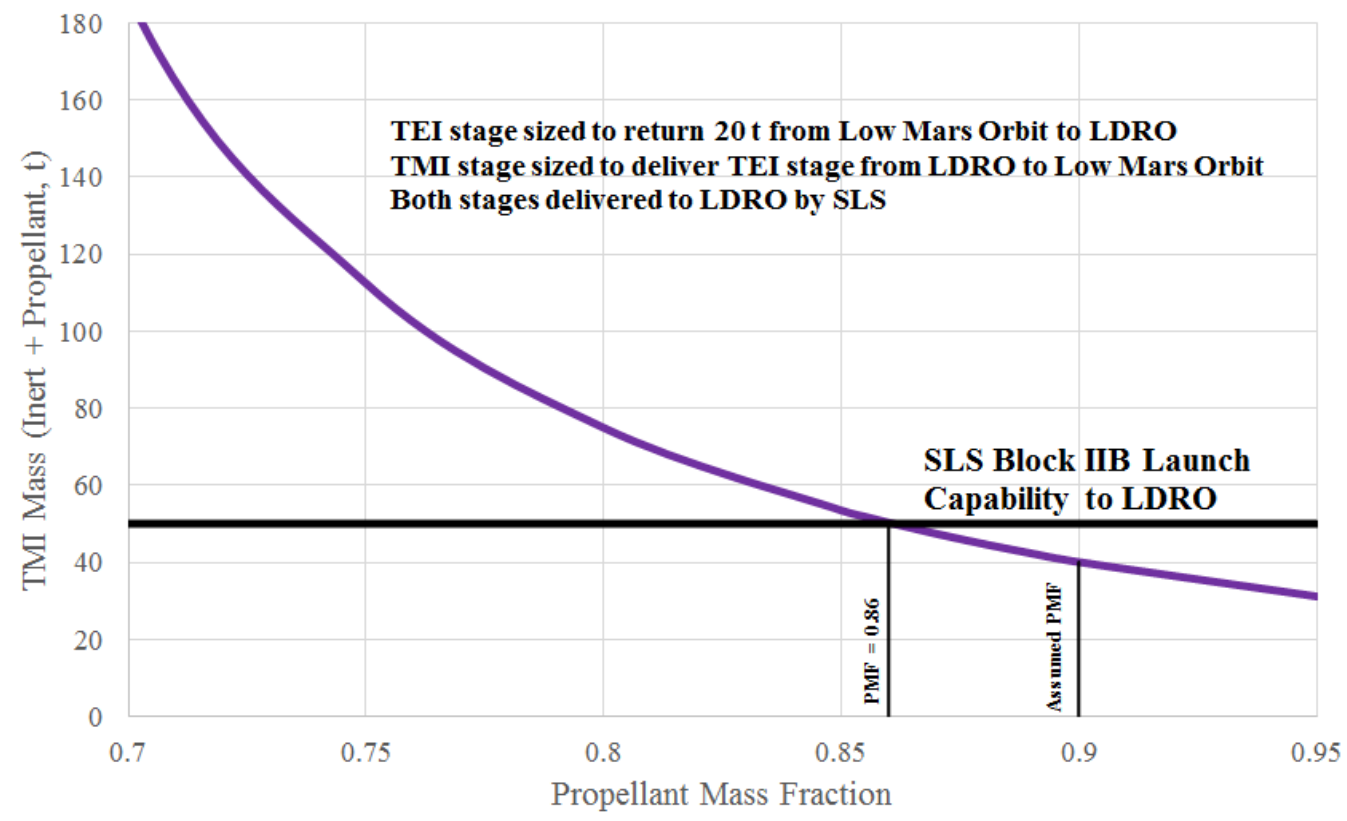

Figure 5: Sensitivity of PMF Assumption on Feasibility with SLS Block IIB 
In the Sustain period, if ISRU-produced propellant is being delivered to LMO, a single reusable vehicle could perform both the TMI/MOI burns and the TEI burn while refueling in LMO. Using the same PMF sizing method, the vehicle to perform this function would be similar in size to the initial TEI stage. Therefore, this initial TEI stage could be scarred to accept propellant on orbit, and the unique disposable TMI/MOI stage could be phased out. This vehicle is presented in Figure 6, and is presented here as one of many options that could be pursued during the Sustain period if ISRU-produced propellant is available in LMO.

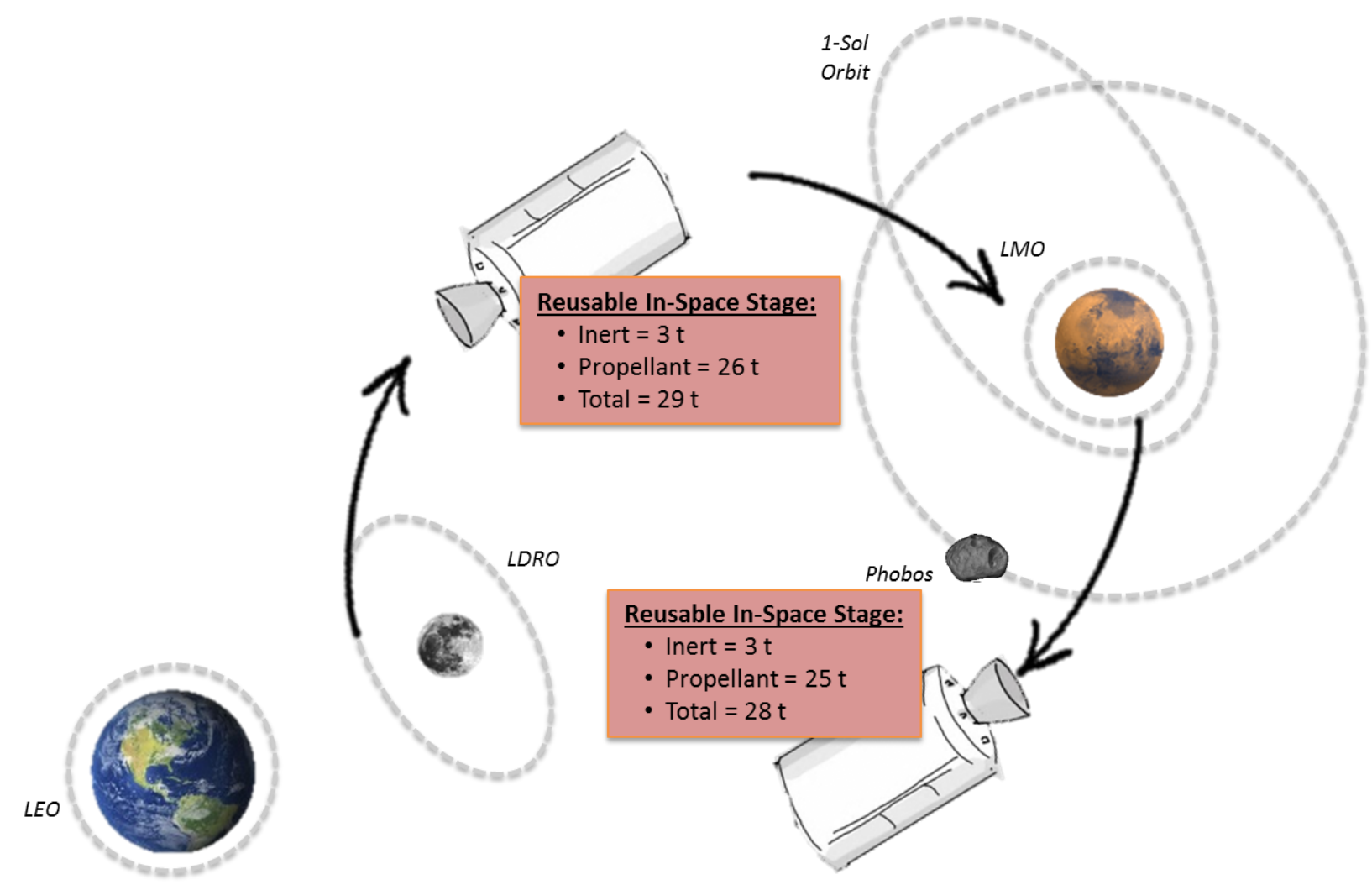

Figure 6: Evolved In-Space Transportation Architecture during Sustain Phase

\section{Mars Planetary Transportation}

1. Initial and Evolved Lander Concepts

The transportation architecture requires an initial landing capability that delivers cargo and crew payloads to Mars surface, yet has the ability to evolve to a high capacity payload delivery capability to enable sustainable growth of the base. Flexibility in the lander design is needed to enable cargo and crew delivery to and from the Mars surface. Assessment of options employing only expendable landers showed the initial landings could occur at lower cost, but the need to build and deliver a new lander for each payload delivered to Mars was more expensive over time.

In response to these needs, an evolvable lander concept is presented that offers initial capability required in the Prepare, Found, and Expand phases that also offers an evolved capability to support the Sustain phase and beyond. For the initial capability, the Hercules SSRL is proposed to deliver cargo and crew to the surface, establishing an initial human presence on Mars and deploying the necessary infrastructure to sustain that presence. As an option, an evolved TSTO configuration is proposed, consisting of the Hercules as the second stage, and a reusable, all-propulsive fly-back booster stage, called Pegasus, as the first stage. This configuration serves to increase the ascent and landed payload capabilities needed to progress into the Sustain phase by decreasing reliance on Earth through the increased use of ISRU, reusability, and automation. 


\section{Lander Design Strategy}

Use of a SSRL places a large propulsive burden on that singular stage, which is assumed to perform $4.1 \mathrm{~km} / \mathrm{s}$ of $\Delta \mathrm{V}$ for ascent. In the baseline configuration, Hercules ascends propulsively to LMO and descends via aeroassisted entry and SRP terminal descent and landing. In addition, reusability implies the vehicle will incur mass penalties to enable extended life, high reliability, and autonomous operations and maintenance. Thus, it is highly desirable to minimize the mass of Hercules to minimize the propellant demand from the Mars ISRU propellant production facility.

Given the exponential relationship between $\Delta \mathrm{V}$ and initial mass in the rocket equation, it is desirable to limit the required $\Delta \mathrm{V}$ on Hercules. Therefore, an LMO parking orbit was selected to limit overall performance requirements on Hercules. Selection of LMO reduces the entry velocity and heating on the lander while also reducing the ascent $\Delta \mathrm{V}$ requirements relative to higher parking orbits, such as the 1-sol orbit used in DRA 5. It should be noted, however, that careful mission planning is required to ensure that the selected parking orbit does not impose significant realignment (plane change) $\Delta \mathrm{V}$ on the interplanetary transportation systems or impose additional ascent or descent performance requirements on Hercules.

The Mars SSTO design space was assessed to understand the expected behavior of the Hercules. Parametric variation of payload down from LMO, lander inert mass, and ballistic coefficient enables maps of required PMF to be constructed assuming an Isp of 360 seconds for $\mathrm{LOX} / \mathrm{CH}_{4}$ propellants. Sizing analysis for Hercules allows the designer to construct available PMF curves. As shown in Figure 7, a range of available PMF curves are shown for a range of assumed heat shield mass fractions (defined as the mass of the shield system divided by the entry mass). The intersection of the available PMF curves with the required PMF map indicates a region of feasible design solutions. The selected design point for Hercules is indicated, which assumes a heat shield fraction of 10 percent, a recurring down payload of $20 \mathrm{t}$, a lander inert mass of $21 \mathrm{t}$, and a ballistic coefficient of $100 \mathrm{~kg} / \mathrm{m}^{2}$. This results in a launch stage mass (from Mars surface) for Hercules around $95 \mathrm{t}$.

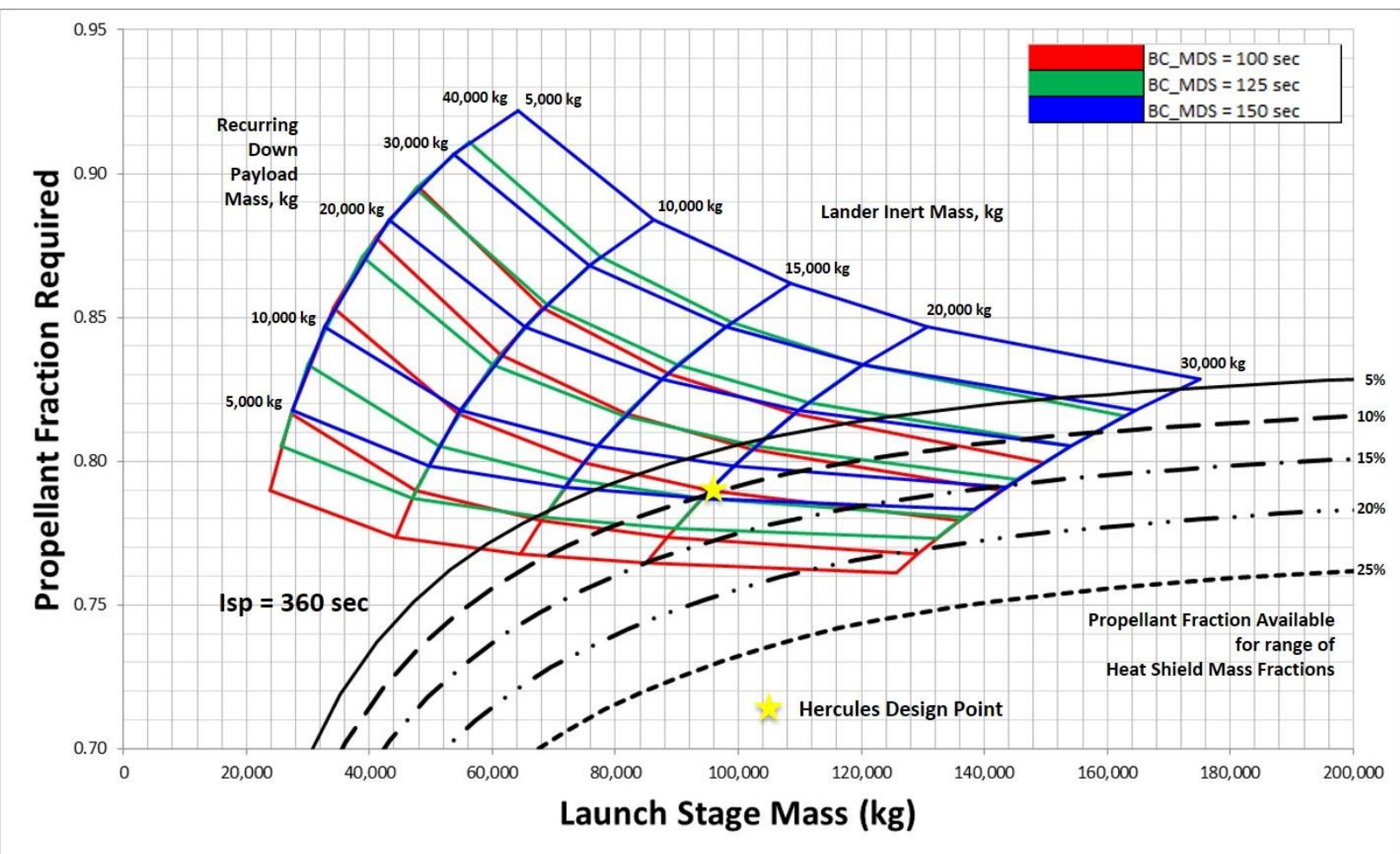

Figure 7: Comparison of Required and Available PMF for Hercules SSTO Design Space

The final Hercules design point utilizes $\mathrm{LOX} / \mathrm{CH}_{4}$ propellants manufactured on Mars surface for ascent, SRP during descent, reaction control system (RCS) throughout the flight, and consumables for fuel cells. Hercules employs a low lift-to-drag sphere-cone heat shield to protect the vehicle during aeroassisted entry, sized such that the entry ballistic coefficient is $100 \mathrm{~kg} / \mathrm{m}^{2}$ for the initial configuration. However, for the evolved configuration, the ballistic coefficient increases to $150 \mathrm{~kg} / \mathrm{m}^{2}$ due to the increased mass at entry $(50 \%$ more due to the increased payload capability). Likewise, during terminal descent and precision landing in the initial configuration, the engine thrust is 
sized to provide a maximum of 3.0 Earth g's deceleration, but for the evolved configuration, the SRP engines provide a maximum of 2.0 Earth g's deceleration. To enable the Hercules to evolve to a TSTO upper stage with increased payload capability, the heat shield and SRP systems must be designed for the higher heat rate, heat load, and burn duration of the evolved system. In addition, the landing mass of the evolved configuration is increased relative to the SSTO lander; thus, the structure and landing legs must accommodate the design requirements of the evolved design. Finally, while the SRP propellant required for the evolved configuration is increased, the fixed propellant tanks of the Hercules requires that less propellant is expended upon ascent in the TSTO configuration. Thus, the Pegasus fly-back booster provides the additional capability to alleviate that burden from the Hercules.

\section{Initial Capability Using Hercules SSRL}

As shown if Figure 8, a partially fueled Hercules lander (along with a 20 metric ton initial payload), is delivered to LMO using the in-space transportation architecture defined in Section V.B in this paper. From LMO, Hercules performs its initial aero-assisted entry that transitions to SRP for terminal descent and precision landing on Mars surface. The initial mission delivers the ISRU infrastructure required by Hercules to receive a full propellant load. During each recurring mission, Hercules ascends (nominally without payload) from Mars surface to LMO, rendezvouses with another $20 \mathrm{t}$ payload, and returns it back to the Mars base. Hercules is also capable of performing a range of alternative missions during the recurring flights phase.

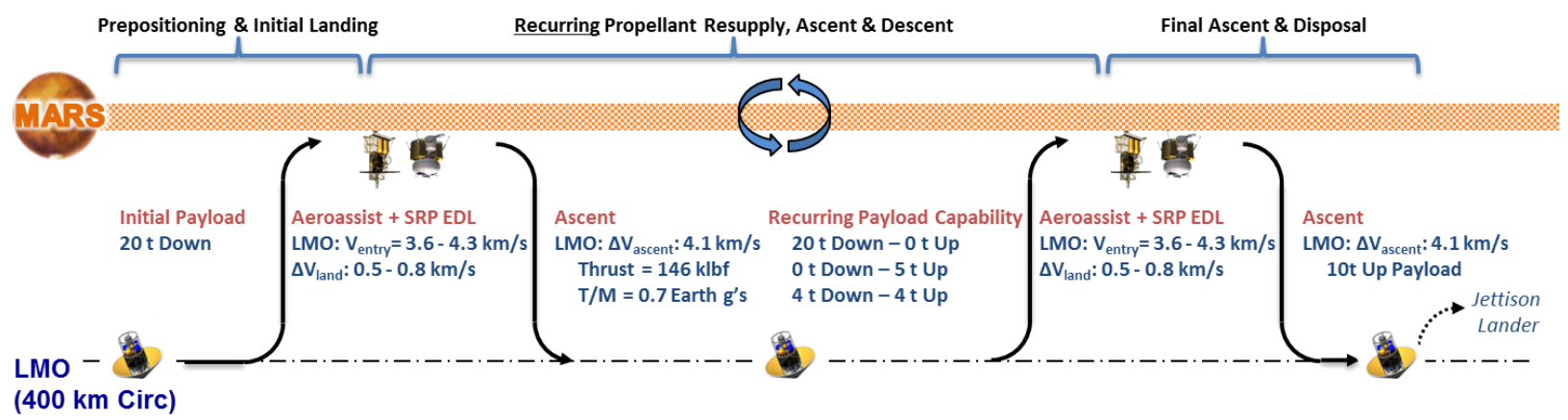

Figure 8: Concept of Operations for Initial Reusable SSTO Lander, Hercules

As described in Table 2, these include a "one-way up payload" mission where nearly $5 \mathrm{t}$ is delivered to LMO, returning to base with no payload, and a "roundtrip payload" mission where nearly $4 \mathrm{t}$ of payload is delivered to LMO and returned to the base. Finally, at its end-of-life, Hercules can deliver up to $10 \mathrm{t}$ to LMO in its "final up-payload" mission and then dispose of itself; alternatively, it could stay on Mars surface and be used for spare parts.

Table 2: Performance of Baseline Hercules Lander

\begin{tabular}{|c|c|c|c|c|c|c|}
\hline & $\begin{array}{l}\text { Reference } \\
\text { Design } \\
\text { for SSRL }\end{array}$ & $\begin{array}{l}\text { Evolved } \\
\text { Design } \\
\text { for TSTO }\end{array}$ & $\begin{array}{l}\text { Initial } \\
\text { Down } \\
\text { Payload }\end{array}$ & $\begin{array}{c}\text { One-Way } \\
\text { Up } \\
\text { Payload }\end{array}$ & $\begin{array}{l}\text { Roundtrip } \\
\text { Up \& Down } \\
\text { Payload }\end{array}$ & $\begin{array}{c}\text { Final } \\
\text { Up } \\
\text { Payload }\end{array}$ \\
\hline $\begin{array}{r}\text { Hercules } \\
\text { Functionality }\end{array}$ & $\begin{array}{r}\text { Propulsive } \\
\text { SSTO and } \\
\text { EDL }\end{array}$ & $\begin{array}{r}\text { TSTO } 2^{\text {nd }}- \\
\text { Stage and } \\
\text { EDL }\end{array}$ & EDL & $\begin{array}{r}\text { Propulsive } \\
\text { SSTO and } \\
\text { EDL }\end{array}$ & $\begin{array}{r}\text { Propulsive } \\
\text { SSTO and } \\
\text { EDL }\end{array}$ & $\begin{array}{r}\text { Propulsive } \\
\text { SSTO }\end{array}$ \\
\hline Ascent Delta- $\mathrm{V}$ & $4.1 \mathrm{~km} / \mathrm{s}$ & $2.2 \mathrm{~km} / \mathrm{s}$ & $\mathrm{n} / \mathrm{a}$ & $4.1 \mathrm{~km} / \mathrm{s}$ & $4.1 \mathrm{~km} / \mathrm{s}$ & $4.1 \mathrm{~km} / \mathrm{s}$ \\
\hline Landing Delta-V & $0.49 \mathrm{~km} / \mathrm{s}$ & $0.87 \mathrm{~km} / \mathrm{s}$ & $0.49 \mathrm{~km} / \mathrm{s}$ & $0.49 \mathrm{~km} / \mathrm{s}$ & $0.49 \mathrm{~km} / \mathrm{s}$ & $\mathrm{n} / \mathrm{a}$ \\
\hline Inert Mass & $21.0 \mathrm{t}$ & $21.0 \mathrm{t}$ & $21.0 \mathrm{t}$ & $21.0 \mathrm{t}$ & $21.0 \mathrm{t}$ & $21.0 \mathrm{t}$ \\
\hline Fuel Mass & $16.8 \mathrm{t}$ & $16.8 \mathrm{t}$ & $1.6 \mathrm{t}(\sim 10 \%)$ & $16.8 \mathrm{t}$ & $16.8 \mathrm{t}$ & $16.8 \mathrm{t}$ \\
\hline Oxid Mass & $57.1 \mathrm{t}$ & $57.1 \mathrm{t}$ & $5.4 \mathrm{t}(\sim 10 \%)$ & $57.1 \mathrm{t}$ & $57.1 \mathrm{t}$ & $57.1 \mathrm{t}$ \\
\hline Stage Mass & $94.9 \mathrm{t}$ & $94.9 \mathrm{t}$ & $28.0 \mathrm{t}$ & $94.9 \mathrm{t}$ & $94.9 \mathrm{t}$ & $94.9 \mathrm{t}$ \\
\hline Up Payload Mass & $0.0 \mathrm{t}$ & $25.0 \mathrm{t}$ & $\mathrm{n} / \mathrm{a}$ & $4.8 \mathrm{t}$ & $3.9 \mathrm{t}$ & $9.9 \mathrm{t}$ \\
\hline Ascent Mass & $94.9 \mathrm{t}$ & $119.9 \mathrm{t}$ & $\mathrm{n} / \mathrm{a}$ & $99.7 \mathrm{t}$ & $98.8 \mathrm{t}$ & $104.8 \mathrm{t}$ \\
\hline Down Payload Mass & $20.0 \mathrm{t}$ & $34.0 \mathrm{t}$ & $20.0 \mathrm{t}$ & $0.0 \mathrm{t}$ & $3.9 \mathrm{t}$ & $\mathrm{n} / \mathrm{a}$ \\
\hline Entry Mass & $48.0 \mathrm{t}$ & $72.0 \mathrm{t}$ & $48.0 \mathrm{t}$ & $24.6 \mathrm{t}$ & $29.2 \mathrm{t}$ & $\mathrm{n} / \mathrm{a}$ \\
\hline
\end{tabular}




\section{Evolved Capability Using Pegasus/Hercules TSTO}

The concept of operations for the Pegasus + Hercules TSTO is shown in Figure 9, which is designed to provide increased payload capability in the Sustain phase and beyond. While this concept is not used in the campaign analysis for this paper, it is presented to describe the evolvable configuration that places requirements on the initial SSTO lander. Pegasus is an all-propulsive stage that uses $\mathrm{LOX} / \mathrm{CH}_{4}$ manufactured at the Mars base. Pegasus performs the first stage of ascent and the powered return to the launch site. As noted above, Pegasus must provide sufficient ascent $\Delta \mathrm{V}$ to deliver the upper stage to a staging point that is within Hercules's fixed $\Delta \mathrm{V}$ capability.

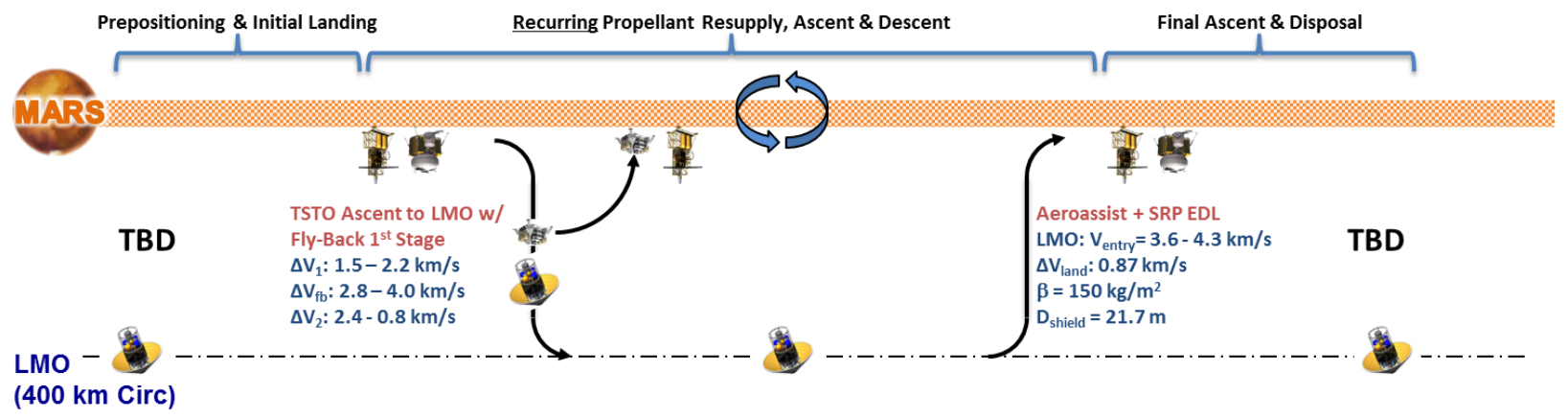

Figure 9: Concept of Operations for Evolved Reusable TSTO Lander, Pegasus and Hercules

At the base, the Pegasus and Hercules stages are mated and both are fully loaded with $\mathrm{LOX} / \mathrm{CH}_{4}$ propellants and consumables produced with Mars ISRU. In the assumed scenario where TEI propellant is delivered to LMO so that the in-space transportation architecture is reusable, Hercules is loaded with $25 \mathrm{t}$ of additional propellant. The TSTO ascends to staging, separates, and the Pegasus booster propulsively returns to the base while the Hercules upper stage continues on to orbit. Once in orbit, Hercules rendezvouses with the TEI stage and transfers the $25 \mathrm{t}$ of propellant required for TEI. In the same flight, Hercules can deliver $34 \mathrm{t}$ of payload back to the Mars surface (ballistic coefficient of $150 \mathrm{~kg} / \mathrm{m}^{2}$; SRP T/W of 2.0 Earth g's). This performance data is presented in Table 2. At the end of its life, Pegasus can, if needed, deliver nearly $50 \mathrm{t}$ of payload to LMO using its full propellant load and dispose itself on Mars surface.

\section{Hercules Design}

Because the intent of the current study is to assess the feasibility of the proposed architecture and campaign using ISRU, reusability, and automation, configuration and design trades for Hercules lander were not performed. Rather, an initial configuration was assumed and sized to estimate the dry mass and quantify the propellant production requirements demanded by the lander. As shown in the notional sketch in Figure 10, the assumed configuration for Hercules is a 60-degree sphere-cone heat shield mounted on top of a liquid propulsion stage that lands vertically on landing legs. The vehicle is fully reusable and includes all subsystems required for Mars ascent, LMO operations, aeroassisted entry, terminal descent and precision landing, and ground operations and turnaround on Mars surface. 


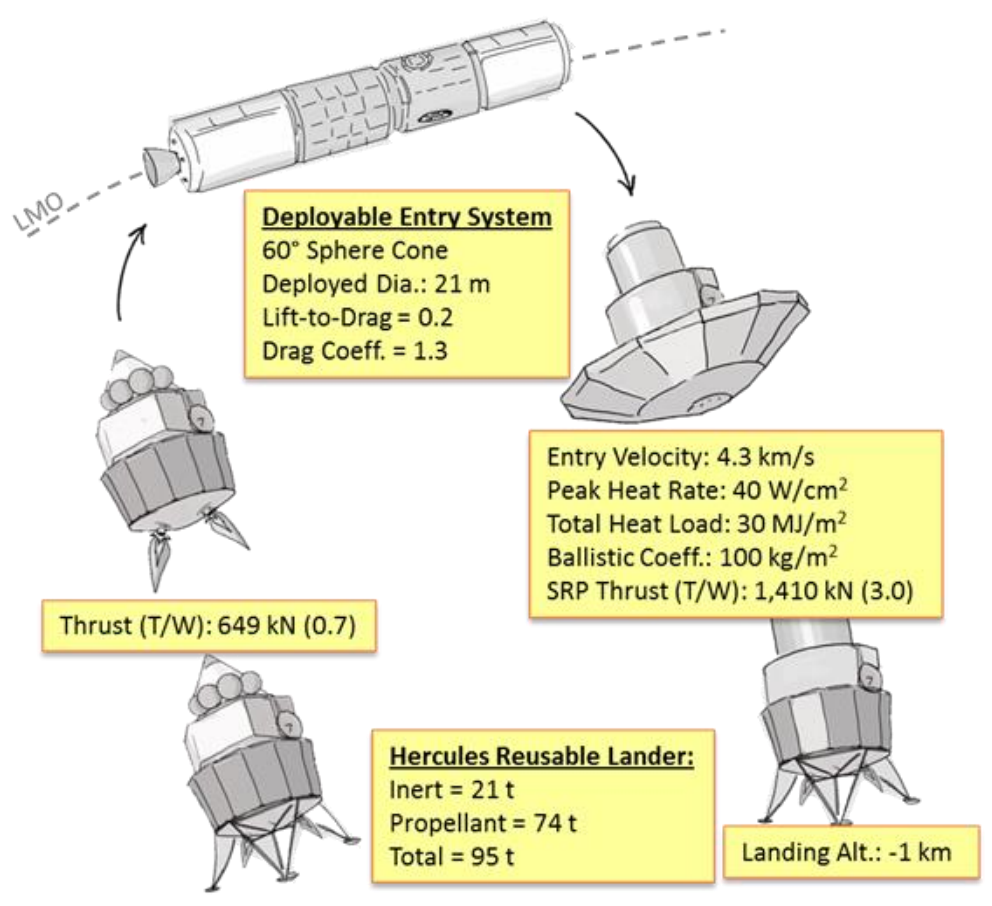

Figure 10: Hercules Configuration Overview

The Program to Optimize Simulated Trajectories version 2 (POST2) trajectory analysis tool was used to estimate the $\Delta \mathrm{V}$ required for Mars ascent, and an in-house MATLAB simulation was used to assess the EDL performance. The EDL analysis assumes the following:

- Entry velocity $=3.7 \mathrm{~km} / \mathrm{s}$ from LMO

- Heat shield diameter sized to ballistic coefficient $=100 \mathrm{~kg} / \mathrm{m}^{2}$

- $\quad$ Drag coefficient $=1.3$

- $\quad$ Lift-to-drag $=0.18$

- $\quad$ Peak deceleration $=3$ g's

- $\quad$ Isp for $\mathrm{SRP}=360 \mathrm{sec}$.

- $\quad$ SRP thrust sized to provide 3 Earth g's initial deceleration

- $\quad$ Landing Altitude $=-1 \mathrm{~km}$ above MOLA

The Exploration Architecture Model for IN-space and Earth-to-orbit (EXAMINE) [17] modeling framework, developed in-house at NASA Langley Research Center, was used to model the mission events and size the lander. Table 3 summarizes the mission events for Hercules as modeled in EXAMINE along with the event-by-event mass requirements resulting from the sizing.

Table 3: Events Summary for Hercules SSRL

\begin{tabular}{|c|c|c|c|c|c|c|c|}
\hline Hercules SSRL Events & $\begin{array}{c}\text { Main }^{1} \\
\Delta \mathrm{V} \\
\mathrm{m} / \mathrm{s}\end{array}$ & $\begin{array}{c}\mathbf{R C S}^{2} \\
\Delta \mathrm{V} \\
\mathrm{m} / \mathrm{s}\end{array}$ & $\begin{array}{c}\text { Initial } \\
\text { Mass, } \\
\text { kg }\end{array}$ & $\begin{array}{c}\text { Final } \\
\text { Mass, } \\
\text { kg }\end{array}$ & $\begin{array}{c}\text { Prop } \\
\text { Mass, } \\
\text { kg }\end{array}$ & $\begin{array}{c}\text { Payload } \\
\text { Mass, } \\
\text { kg }\end{array}$ & $\begin{array}{c}\text { Stage } \\
\text { Mass, } \\
\text { kg }\end{array}$ \\
\hline Ascent to Insertion at $100 \mathrm{~km} \times 250 \mathrm{~km}$ & 4,264 & 10.5 & 94,242 & 27,854 & 66,388 & 0 & 94,242 \\
\hline Orbit Transfer to $250 \mathrm{~km} \mathrm{x} 400 \mathrm{~km}$ & 0 & 84.5 & 27,854 & 27,124 & 730 & 0 & 27,854 \\
\hline Orbit Transfer to $400 \mathrm{~km} \mathrm{x} 400 \mathrm{~km}$ & 0 & 46.2 & 27,124 & 26,734 & 391 & 0 & 27,124 \\
\hline Orbit Maintenance & 0 & 31.5 & 46,734 & 46,273 & 460 & 20,000 & 26,734 \\
\hline De-Orbit \& Re-Orient for Entry & 0 & 91.9 & 46,273 & 44,957 & 1,316 & 20,000 & 26,273 \\
\hline Retro-Propulsion for Terminal Landing & 513 & 52.5 & 44,957 & 38,136 & 6,821 & 20,000 & 24,957 \\
\hline
\end{tabular}

Note 1 - includes $4 \%$ additional margin on delta-V for flight performance uncertainties

Note 2 - includes $5 \%$ additional margin on delta-V for flight performance uncertainties 
Given the low heat rates and heat load of Hercules entry, a mechanically deployed, hot structure concept is the baseline for the reusable heat shield. Detailed design and sizing of the heat shield was not performed in this feasibility study. Instead, based on similar studies and designs [18], the heat shield mass fraction was assumed to be $10 \%$ of the entry mass.

For the main propulsion system (MPS), four pump-fed $\mathrm{LOX} / \mathrm{CH}_{4}$ engines are assumed and are sized to deliver a total of 3 Earth g's deceleration at the initiation of the SRP phase. This results in four $334 \mathrm{kN}$ engines that must be throttled to about $10 \%$ at landing. For ascent about 1.4 Earth g's of thrust is available, but optimization of the ascent trajectory indicates that only 0.7 Earth g's is needed. Thus, substantial engine-out capability is available during the ascent phase where either two engines operate at $100 \%$ or all four engines operate at $50 \%$ throttle.

Using the mass estimating relationships in EXAMINE, the rest of the Hercules lander was sized based on its performance requirements, and the results for the inert mass components are presented in Table 4 along with discussion on the sizing rationale. Table 5 shows the propellant mass breakdown for Hercules, by propulsion subsystem, and a summary of the gross mass at key mission events.

Table 4: Hercules Inert Mass Sizing Overview

\begin{tabular}{|c|c|c|}
\hline Stage Inert Mass Breakdown & Mass, kg & Comments \\
\hline Dry Mass w/ Growth & 15,156 & \\
\hline Structures & 4,377 & \\
\hline Primary & 1,244 & $8.8 \mathrm{~m}$ diameter; composite structures \\
\hline Secondary & 304 & $5 \%$ of total structure mass \\
\hline Tank Support & 386 & $0.5 \%$ of supported tank + propellant mass \\
\hline Payload Support & 500 & $2.5 \%$ of supported payload mass \\
\hline Thrust Structure & 606 & Composite structure \\
\hline Landing Legs & 1,338 & $3.5 \%$ of landed mass \\
\hline Deployable Heat Shield & 4,496 & $10 \%$ of entry mass \\
\hline Main Propulsion System (MPS) & 3,738 & \\
\hline Fuel Tanks \& Feed & 1,127 & \multirow{2}{*}{$\begin{array}{l}4 \text { fuel and } 2 \text { oxidizer cylindrical aluminum-lithium tanks at } \\
275 \mathrm{kPa} \text { w/ MLI for passive thermal control on-orbit }\end{array}$} \\
\hline Oxidizer Tanks \& Feed & 1,155 & \\
\hline Pressurization Systems & 107 & Autogenous system using engine heat exchanger \\
\hline Engines & 1,349 & $4 \times 334 \mathrm{kN}$ pump-fed engines delivering $360 \mathrm{sec}$ Isp \\
\hline Reaction Control System (RCS) & 478 & \\
\hline Fuel Tanks \& Feed & 149 & \multirow{2}{*}{$\begin{array}{l}8 \times 1,550 \mathrm{kPa} \text { spherical graphite-wrapped aluminum tanks } \\
\text { w/ MLI for passive thermal control on-orbit }\end{array}$} \\
\hline Oxidizer Tanks \& Feed & 188 & \\
\hline Pressurization Systems & 8 & $2 \times 41 \mathrm{MPa}$ spherical graphite-wrapped aluminum tanks \\
\hline Thrusters & 134 & $16 \times 445 \mathrm{~N}$ pressure-fed thrusters delivering $325 \mathrm{sec}$ Isp \\
\hline Power, Thermal \& Avionics & 677 & \\
\hline Solid Oxide Fuel Cells & 116 & $3 \times 2 \mathrm{~kW}$; consumables scavenged from MPS residuals \\
\hline Power Mgmt \& Distribution & 91 & $400 \mathrm{~Hz}, 115$ volt AC w/ 10 kW peak power @ 90\% eff. \\
\hline Heat Acquisition \& Transport & 176 & Ammonia fluid loop collecting $6 \mathrm{~kW}$ heat \\
\hline Heat Rejection & 95 & Body-mounted radiator rejecting $6 \mathrm{~kW}$ \\
\hline Command \& Control & 44 & \\
\hline Guidance \& Navigation & 47 & \\
\hline Communications & 74 & \\
\hline Cabling \& Instrumentation & 35 & \\
\hline Mass Growth Allowance & 1,391 & $15 \%$ of dry mass \\
\hline Unusable Propellants & 2,980 & \\
\hline RCS Reserves & 197 & $5 \%$ of usable propellant \\
\hline RCS Residuals & 79 & $2 \%$ of usable propellant \\
\hline RCS Helium Pressurant & 38 & \\
\hline MPS Residuals & 2,165 & $3 \%$ of usable propellant \\
\hline MPS Boiloff & 0 & \\
\hline MPS Autogenous Pressurant & 501 & \\
\hline Inert Mass & $\mathbf{1 8 , 1 3 6}$ & \\
\hline
\end{tabular}


Table 5: Hercules Propellant and Gross Mass Summary

\begin{tabular}{|l|r|}
\hline Stage Propellant Mass Breakdown & Mass, kg \\
\hline Inert Mass & $\mathbf{1 8 , 1 3 6}$ \\
\hline Payload - Landed & 20,000 \\
\hline Landed Mass & $\mathbf{3 8 , 1 3 6}$ \\
\hline Propellant - Retro-Propulsion & 6,821 \\
\hline Entry Mass & $\mathbf{4 4 , 9 5 7}$ \\
\hline Propellant - De-Orbit \& Entry Orientation & 1,316 \\
\hline De-Orbit Mass & $\mathbf{4 6 , 2 7 3}$ \\
\hline Propellant - Orbit Maintenance & 460 \\
\hline Parking Orbit Mass & $\mathbf{4 6 , 7 3 4}$ \\
\hline Payload - Picked up in LMO & $-20,000$ \\
\hline Initial Parking Orbit Mass & $\mathbf{2 6 , 7 3 4}$ \\
\hline Propellant - Orbit Transfer to 400 km x 400 km & 391 \\
\hline Propellant - Orbit Transfer to 250 km x 400 km & 730 \\
\hline Propellant - Mars Ascent to 100 km x 250 km & 66,388 \\
\hline Ascent Mass & $\mathbf{9 4 , 2 4 2}$ \\
\hline
\end{tabular}

\begin{tabular}{|r|r|r|r|}
\hline \multicolumn{2}{|c}{ MPS } & \multicolumn{2}{c|}{ RCS } \\
\multicolumn{1}{|c|}{ Fuel } & Oxidizer & \multicolumn{1}{c|}{ Fuel } & Oxidizer \\
\hline 1,368 & 4,718 & 165 & 570 \\
\hline & & & \\
\hline 0 & 0 & 296 & 1,021 \\
\hline & & & \\
\hline 0 & 0 & 103 & 357 \\
\hline & & & \\
\hline & & & \\
\hline 0 & 0 & 88 & 303 \\
\hline 0 & 0 & 164 & 566 \\
\hline 14,849 & 51,229 & 70 & 241 \\
\hline $\mathbf{1 6 , 2 1 6}$ & $\mathbf{5 5 , 9 4 7}$ & $\mathbf{8 8 6}$ & $\mathbf{3 , 0 5 7}$ \\
\hline
\end{tabular}

\section{Pegasus Design}

A configuration for the optional Pegasus fly-back booster was not analyzed in detail. Rather, in an effort to assess the viability of an ISRU-fueled TSTO using a liquid fly-back booster, a POST2 trajectory simulation and sizing analysis was performed to identify a reasonable design target for the Pegasus concept assuming the following propulsion capabilities:

- $\quad \mathrm{LOX} / \mathrm{CH}_{4}$ propellant at mixture ratio $=3.45$ delivering Isp $=360$ seconds

- Thrust sizing based on initial T/W =0.7 Earth g's (1.87 Mars g's) at liftoff

The preliminary POST2 trajectory simulating the TSTO ascent and fly-back was used to predict mass ratio and $\Delta \mathrm{V}$ performance required for Pegasus. Based on the capability of the initial configuration, Hercules can perform the final $2.2 \mathrm{~km} / \mathrm{s}$ in a TSTO configuration ( $\Delta \mathrm{V}$ from staging to insertion in LMO). Therefore, Pegasus booster must provide the initial $1.8 \mathrm{~km} / \mathrm{s}$ to deliver Hercules to the staging point. In addition, the fly-back itself back to the Mars base requires an additional $\Delta \mathrm{V}$ of $3.3 \mathrm{~km} / \mathrm{s}$. Results of the POST2 analysis were targeted solutions but were not optimized; future efforts could optimize these ascent and fly-back branching trajectories.

Utilizing this performance data, a sizing analysis was performed to estimate the inert and propellant mass required for Pegasus as a function of TSTO payload performance. First, EXAMINE was used to develop an available PMF trend curve for Pegasus as a function of maximum loaded propellant. Using the trajectory data from POST2 and the sizing data from EXAMINE, a sensitivity was performed to determine the mass of Pegasus as a function of the payload delivered to orbit. Figure 11, which plots the inert and propellant mass required as a function of TSTO payload, shows that for a $25 \mathrm{t}$ payload (selected based on the desire to deliver Mars propellant to the TEI stage in LMO), the Pegasus inert mass is $26.4 \mathrm{t}$ and the total propellant mass at liftoff is $178.6 \mathrm{t}$. The $205 \mathrm{t}$ stage requires a minimum PMF of 0.871. Further assessment of the optional Pegasus/Hercules TSTO is needed - specifically to quantify the need for the evolved capability and whether Pegasus can be developed, delivered, and operated as designed to realize the goals of the Sustain phase. 


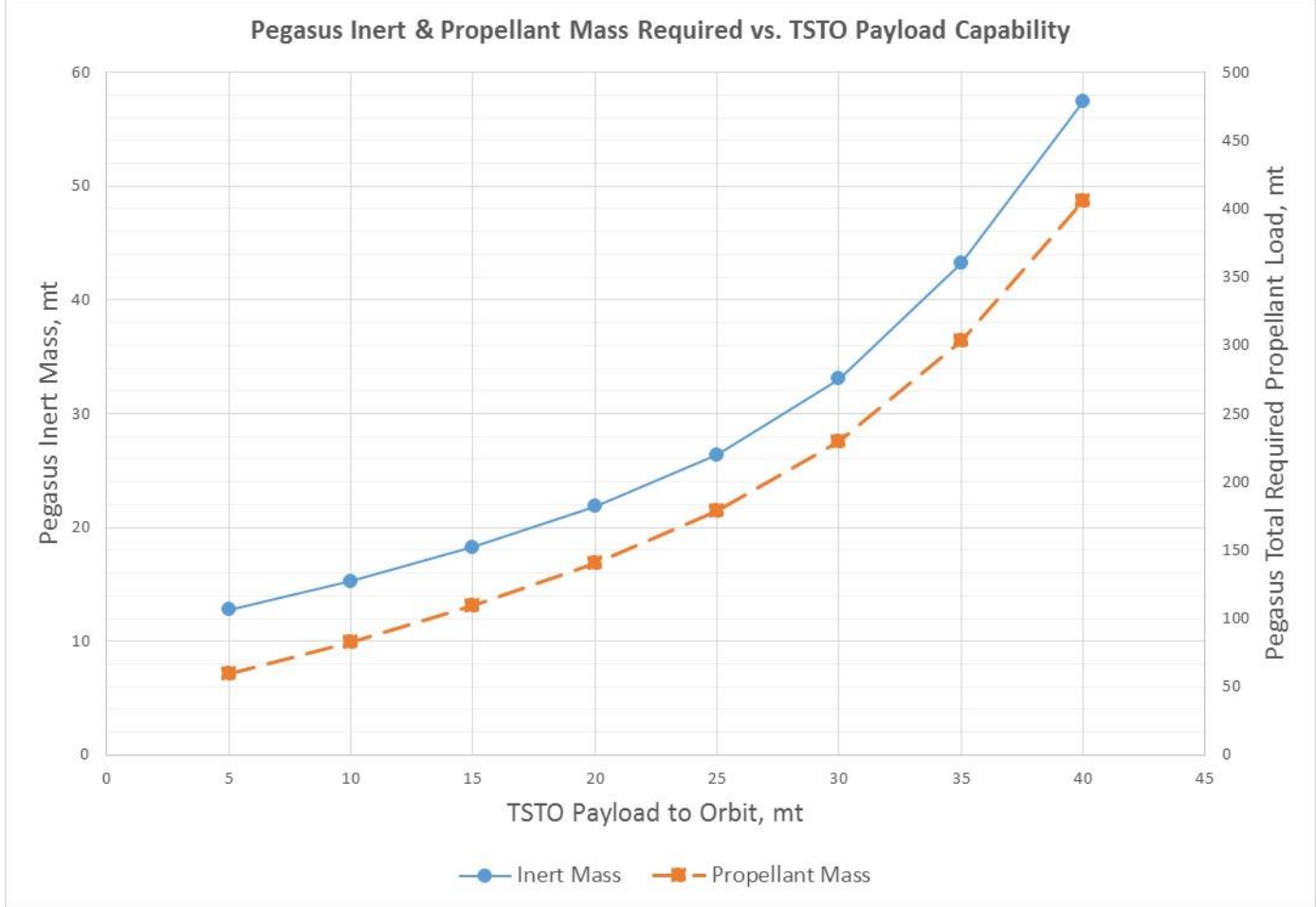

Figure 11: Pegasus Mass Sensitivity to Delivered Payload Mass

\section{Campaign Analysis}

In order to quantify the impact that the initial transportation and surface architecture configurations have on facilitating a sustained human presence on Mars, a campaign analysis was performed comparing three separate campaign strategies. These strategies build a campaign starting from the Prepare phase and continue to the steady state base size. The first, the Disposable Lander Campaign, utilizes disposable landers and limited ISRU. The second, the Light ISRU Campaign, utilizes the reusable lander Hercules, but limits the ISRU production to enough propellant for one flight per year; this campaign reveals the impact of a reusable Mars lander on building a sustained human presence on Mars. Finally, the third, the Extensive ISRU Campaign, utilizes Hercules and ISRU produces propellant for two flights per year and many consumables. It is important to note that none of the three campaigns utilize the reusable in-space propulsion system or the Pegasus booster.

\section{A. Assumptions for All Campaigns}

\section{Transportation}

Each campaign assumes two SLS launches per year, with the occasional surge to three. Each launch is capable of delivering either $40 \mathrm{t}$ in a few days or $50 \mathrm{t}$ in 18 months to an LDRO. All elements aggregate at LDRO until a Mars departure opportunity occurs. The available Mars opportunities occur every 26 months and are defined as conjunctionclass missions, which have relatively low $\Delta \mathrm{V}$ requirements $(\sim 2.6 \mathrm{~km} / \mathrm{s}$ total between LDRO and LMO), typical surface durations over 500 days, and trip times of 6 to 7 months each way. The payload capacity to $\mathrm{LMO}$ using the $\mathrm{LOX} / \mathrm{CH}_{4}$ TMI/MOI stages range from $28 \mathrm{t}$ (one stage) to $66 \mathrm{t}$ (two stages). Once at Mars, the lander is capable of delivering 20 $\mathrm{t}$ to Mars surface.

\section{Surface Elements}

All campaigns have a similar base set of surface elements. The habitation of the crew is comprised of a single core habitat featuring a closed-loop Environmental Control and Life Support System (ECLSS). Closed-loop ECLSS is a system with some consumable (water and gases) recovery or generation from the available resources/waste within the habitat. In addition to the core habitat, a logistics carrier can be converted into additional habitable volume after it has been emptied of the logistics.

The power supply is a surface nuclear reactor that is sized appropriately based on the individual campaign needs for initial ISRU and the first crewed mission. In addition, a pressurized rover, payload reposition system, starter power system, and power distribution unit are delivered to support the first crewed mission. A power cable is required for 
the lander, habitat, each ISRU plant, and logistic carriers. A maximum of four logistic carriers are attached to the habitat at any one point, and can be converted to additional living space while the rest are discarded after use and replaced by the next carrier.

\section{Logistics}

Because the length of the campaigns are over 20 years with multiple crewed missions, logistics are a driving factor in launch mass requirements after the initial infrastructure is deployed. Logistics are required for crew survival and include water, oxygen, methane, food, plastics, other consumables, spares and maintenance supplies. The other consumables are required items that cannot initially be readily made on Mars, such as emergency kits, operational supplies, clothing, and specific spares and maintenance parts. The logistics for the campaigns utilize the same assumptions as the Evolvable Mars Campaign (EMC). The consumption rates, packaging, and ECLSS options used in this analysis are based on cis-lunar values from Lopez et al. [19] and on-going work to derive Mars logistics requirements. Table 6 details the consumable rates used in this analysis.

Table 6: Consumable Consumption Rates
\begin{tabular}{|cc|}
\hline \multicolumn{2}{|c|}{ Units } \\
\hline Oxygen Requirements \\
\hline $\mathrm{kg}$ & Varies $^{8}$ \\
\hline $\mathrm{kg}$ per crew-day & 0.82 \\
\hline kg per EVA hour & 0.09 \\
\hline Water Requirements \\
\hline kg per crew-day \\
\hline kg per day \\
\hline kg per EVA hour \\
\hline Nitrogen Requirements \\
\hline kg \\
\hline Food Requirements \\
\hline kg per crew-day \\
\hline Other Requirements \\
\hline kg per crew-day \\
\hline kg per crew \\
\hline
\end{tabular}

All the consumables require packaging to be transported to Mars, and the packaging mass (Table 7) varies based on the type of consumable. The water and gases are carried in Shuttle-era tanks while the food and other consumables are packaged in Cargo Transfer Bag Equivalents (CTBEs) and then placed in a Pressurized Logistics Module (PLM) for launch and transportation.

Table 7: Packaging Assumptions

\begin{tabular}{|lcc|} 
Consumable & Carrier Mass (kg) & Capacity (kg) \\
\hline Oxygen & 50 & 50 \\
\hline Nitrogen & 50 & 50 \\
\hline Water & 35 & 210 \\
\hline CTBE & 2 & 20 \\
\hline PLM & 3,220 & 5,500 \\
\hline
\end{tabular}

\section{B. Disposable Lander Campaign}

\section{Philosophy}

In the Disposable Lander Campaign, the Mars lander is used once to deliver crew or cargo to the Mars surface. Similar to EMC and DRA 5, an ascent vehicle utilizes liquid oxygen produced by a single surface ISRU plant, which is sized to generate the required propellant to ascend before the crew arrives at Mars. The purpose of the Disposable Lander Campaign is to provide a point of departure to determine the effects of reusability and different levels of ISRU production on a sustained Mars campaign.

\footnotetext{
${ }^{8}$ Function of habitat (volume, pressure, oxygen/nitrogen percent, leak rate) and EVAs (number, recapture rate)
} 


\section{Campaign Specific Assumptions}

The first Mars lander delivers the oxygen ISRU plant and surface nuclear reactor, sized to generate $40 \mathrm{kWe}$, which is sufficient to operate the oxygen ISRU plant. Once the oxygen is created and the surface habitat is delivered, the power plant transitions to power generation for the surface habitat. A second plant is delivered before the second crew mission, and the oxygen ISRU plant can continuously operate to supply the oxygen for ascent and support the habitat while the crew is present. The Disposable Lander Campaign also assumes a single Surface Pressurized Rover (SPR) since the campaign never exceeds four crew on the surface. The TMI stage is capable of delivering the disposable lander and $20 \mathrm{t}$ payload. To deliver the first crew, TMI stages delivers the crew, transit habitat, TEI stage, and disposable lander to LMO prior to crewed descent to Mars.

\section{Results}

Due to the nature of a disposable lander, an ascent vehicle and lander must be sent every crewed mission. This design requires at least two launch vehicles because the sum of the TMI stage (34t), disposable lander (27.7 t), and payload (20 t) to LDRO exceeds a single SLS capability. There are an additional eight elements that need to be delivered every conjunction-class crewed mission: four TMI stages; a TEI stage; a transit habitat; a lander for the crew; and Orion to deliver the crew to LDRO. Of these elements, only the transit habitat can be delivered to LDRO with another large element without exceeding the mass capability of an SLS to LDRO. Therefore, a minimum of nine launches is required for every crew mission to Mars; this does not include the logistics to support the crew once at Mars. Because a Mars opportunity occurs approximately every two years, and under the assumption of two SLS launches every year with an occasional surge to three, a crew mission can only occur every other Mars opportunity (i.e., every four years).

Figure 12 presents a summary of the Disposable Lander Campaign results. The cumulative number of launches is consistent with a flight rate of two per year with the occasional surge to three. The number of crew on the surface shows the number of crew at the Mars base at any given time. The launch constraint ultimately becomes the limiting factor to the Disposable Lander Campaign, which can only support a crew mission to Mars every four years. The missions are a 500-day surface stay with long dormancy periods (about 3 years) between each period.

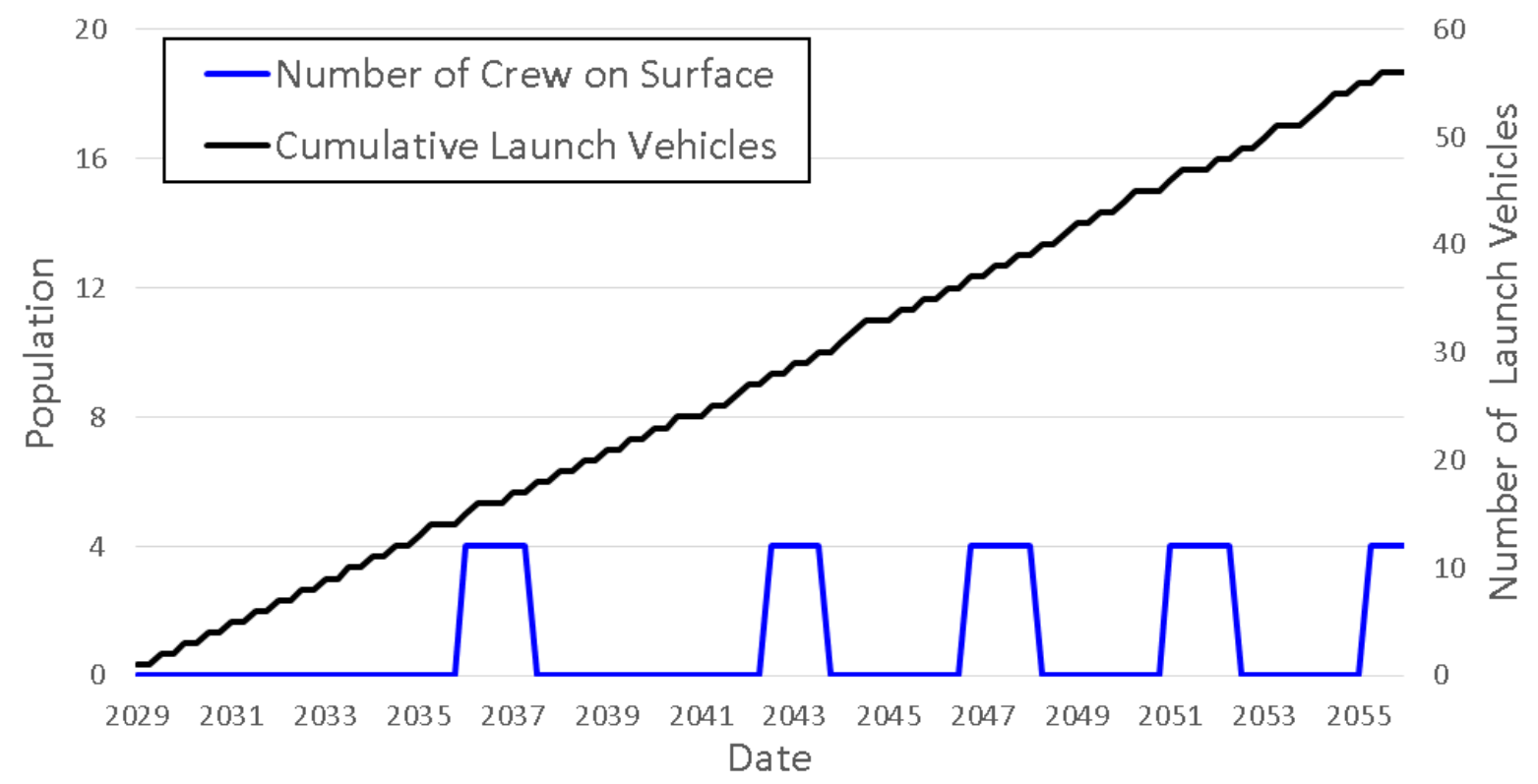

Figure 12: Disposable Lander Campaign Results Summary

\section{Light ISRU Campaign}

\section{Philosophy}

The Light ISRU campaign builds from the Disposable Lander Campaign by investing in the reusable lander, Hercules, and associated ISRU-production of oxygen and methane propellant. There are two plants, atmospheric and regolith, delivered on the first Mars cargo mission. Together, both plants produce the oxygen and methane required for one ascent and descent per year. An added benefit to the regolith plant is the production of water which can be utilized by the crew for other needs. Hercules and the associated ISRU investments are the first steps to becoming Earth-independent on Mars. 


\section{Campaign Specific Assumptions}

The Light ISRU Campaign requires higher level of ISRU production than the Disposable Lander Campaign and therefore has a higher power requirement. Thus, two power plants sized for $110 \mathrm{~kW}$ each are delivered prior to the first crew mission to Mars. The power plants support the habitat, logistics, and the ISRU plants. An additional SPR is also delivered to the surface because the Light ISRU Campaign has near continuous presence and it is assumed the crew will have increased available time to perform excursions. Two TMI stages are used in conjunction to deliver the elements to LMO, where the elements aggregate until Hercules is able to collect the elements at LMO and return with them to the surface.

\section{Results}

When compared to the Light ISRU Campaign, the reusable lander and ISRU plants replace the need for a disposable lander, a TMI stage, and an SLS launch required each time elements or logistics are delivered to the Mars surface. This changes the delivery of elements and logistics operations; now the payload is delivered to LMO, where it loiters until Hercules is able to bring it to the surface.

Figure 13 presents the resulting data for the Light ISRU Campaign. The one-per-year flight rate of the Hercules is the limiting factor in population growth for this campaign. In addition, the required mass delivered to LDRO is greatly reduced (greater than $27 \mathrm{t}$ for each lander required); therefore, the required number of launches are reduced. The launch savings is utilized to deliver crew to Mars surface at every opportunity rather than every other one, which creates a near continuous human presence on Mars. However, only creating propellant and water on Mars is insufficient to grow the population beyond four crew members.

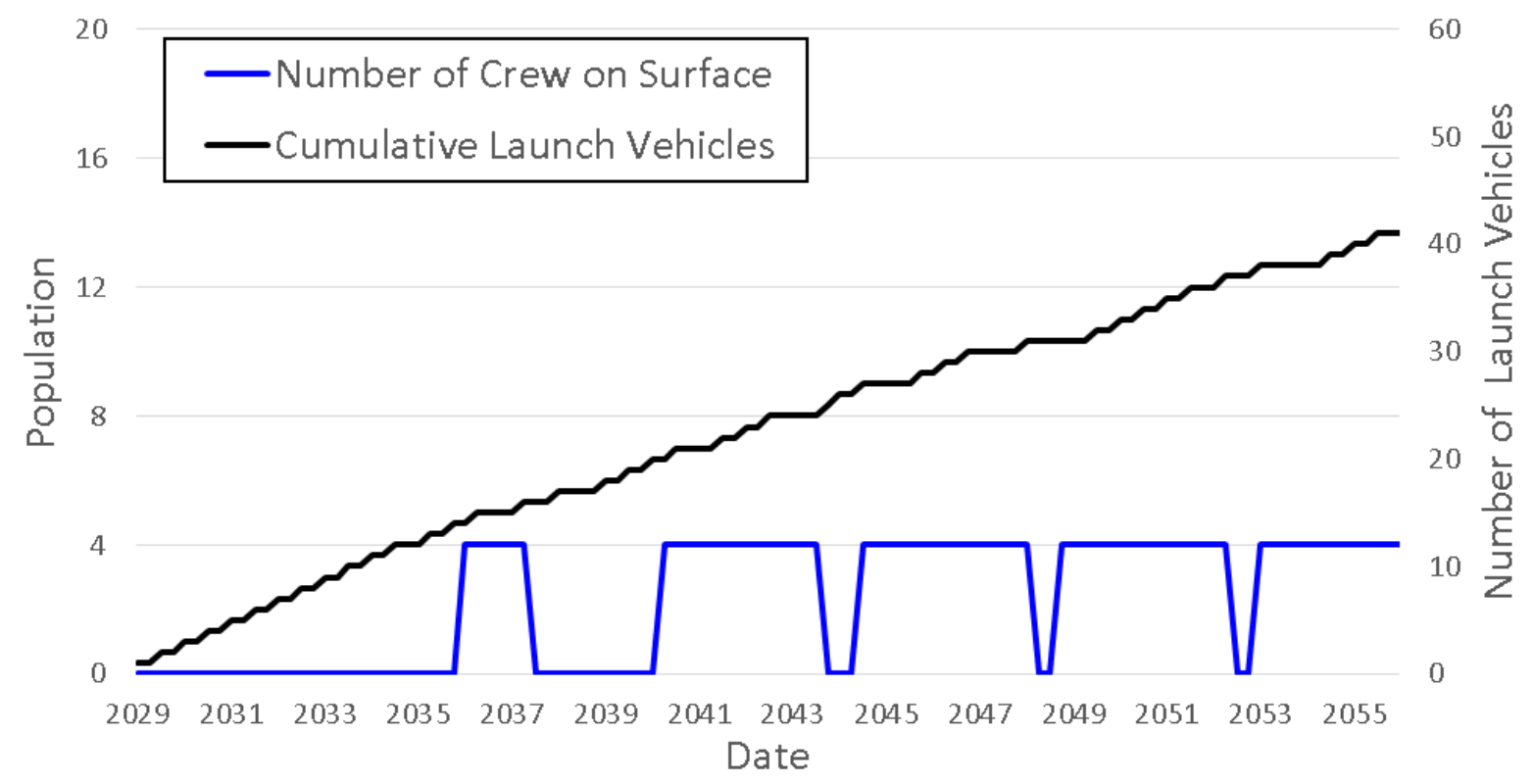

Figure 13: Light ISRU Campaign Results Summary

\section{Extensive ISRU Campaign}

\section{Philosophy}

The Extensive ISRU Campaign builds upon the Light ISRU Campaign by increasing ISRU production and decreasing Earth dependence. The Light ISRU Campaign is restricted by Hercules being limited to one ascent/descent per year, while the Extensive ISRU Campaign increases ISRU production to support two ascents/descents per year. In addition to increasing the propellant production, additional ISRU plants for other crew consumables (food, nitrogen, plastics) are delivered as well. While the intent is to become Earth-independent, some logistics are supplied from Earth that cannot be produced on Mars without significantly more infrastructure established, such as spares and maintenance parts that cannot be built from plastics or food that supplements the algae production.

The campaign focuses on increasing the number of humans at Mars, building on the near continuous human presence that is established in the Light ISRU Campaign. The build-up of humans at Mars is done through a strategy in which each crew stays on Mars one opportunity longer than the previous crew. For example, the first crew mission stays for the approximate 500 days and leaves when the first conjunction class opportunity appears. The second crew 
mission to Mars will stay until the second return opportunity after that crew arrives. This increase continues until there are 4 crews (16 crew members) at Mars simultaneously.

\section{Campaign Specific Assumptions}

Compared to the Light ISRU Campaign, an additional pair of regolith and atmospheric plants are delivered to produce $\mathrm{LOX} / \mathrm{CH}_{4}$ for two ascents/descents of Hercules per year and extra oxygen and water for crew consumption. Three algae production plants are delivered to supplement the food supply; six plastic production plants generate raw material for spares, maintenance, and other consumables; and six nitrogen production plants produce buffer gasses for the habitat. To support the additional ISRU plants, four $110 \mathrm{~kW}$ power plants are delivered to the Mars surface. The elements are delivered over the entire campaign to balance the needs as the number of crew increases. Prior to the first crew mission, the elements are the same as the Light ISRU Campaign with the exception of the added nitrogen plant. The additional Hercules flight per year enables more infrastructure to be emplaced as the crew population grows.

3. Results

Figure 14 presents the results for the Extensive ISRU Campaign, where the cumulative number of launches remain at the 2-per-year flight rate for SLS and the total number of crew increases to 16, which the infrastructure can maintain indefinitely. The additional ISRU production and reusable lander reduce the dependency upon Earth, and the SLS launches can be focused on delivering crew every Mars opportunity beginning with the second crew mission until the population reaches 16 crewmembers. At that size, the SLS launch rate cannot support additional crew while also supplying the required Earth-based consumables to support the larger population. The population can surge to 20 briefly before the consumable requirements from Earth exceed those that can be supplied under the current launch assumptions. Therefore, to support growth beyond this size, either more items will need to be produced at Mars or the launch and in-space transportation infrastructure will need to be upgraded to deliver more consumables to LMO.

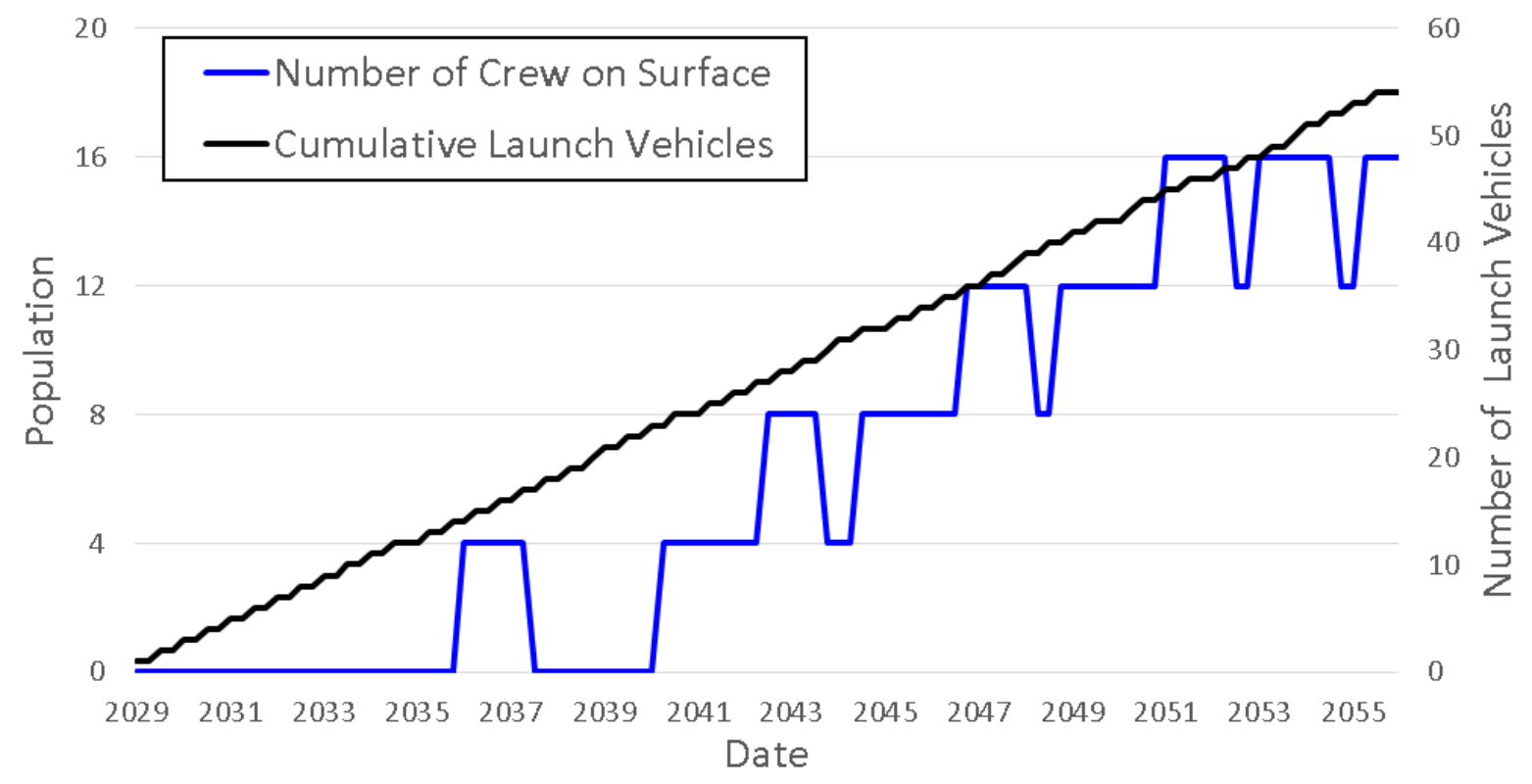

Figure 14: Extensive ISRU Campaign Results Summary

\section{E. Comparison of Campaigns}

Comparisons between the three campaigns are presented in the following figures. Figure 15 presents the launch cadence for each of the three campaigns. The Extensive ISRU Campaign uses the two SLS launches per year, and the Disposable Campaign requires more launches than the two ISRU campaigns because it surges to the third SLS on occasion. Due to the constraint on Hercules flights, the Light ISRU Campaign is not capable of landing a full SLS launch capacity and therefore the number of SLS launches in Figure 15 is significantly less than either of the other two campaigns. 


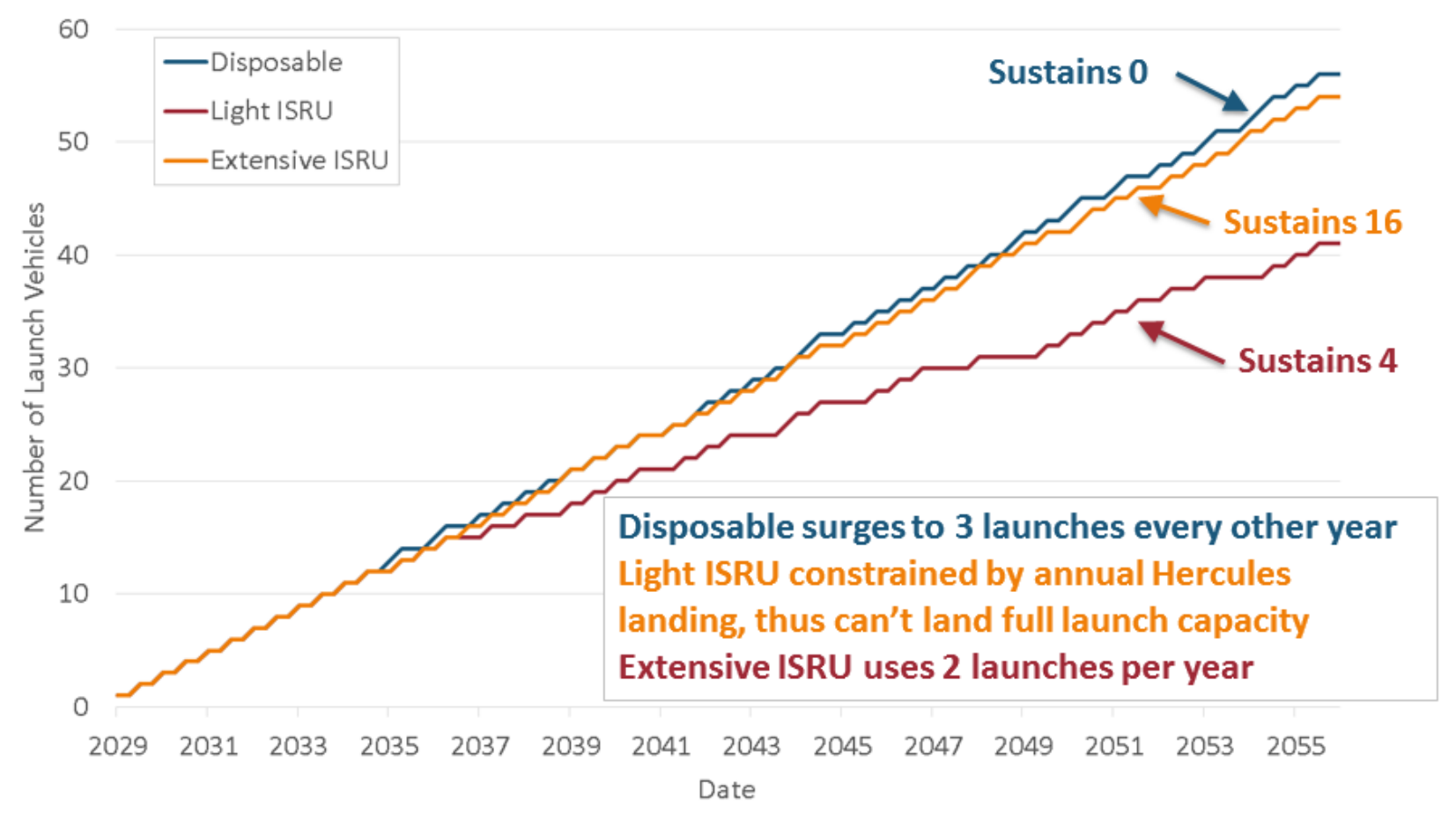

Figure 15: Comparison of Cumulative Number of Launches

Figure 16 presents the crew size at any given time for the three campaigns. The Mars population for the Disposable campaign is a series of 500-day surface stay missions with long dormancy periods (approximately three years) between each mission. In the Light ISRU Campaign, the population on Mars is constrained by limited availability of surface descents to deliver enough logistics, but is capable of sustaining a near continuous presence of four crew. The population on Mars for the Extensive ISRU Campaign is limited to a sustained crew of 16 within the SLS and inspace transportation constraints and assumptions (for delivery of supplies not produced by ISRU).

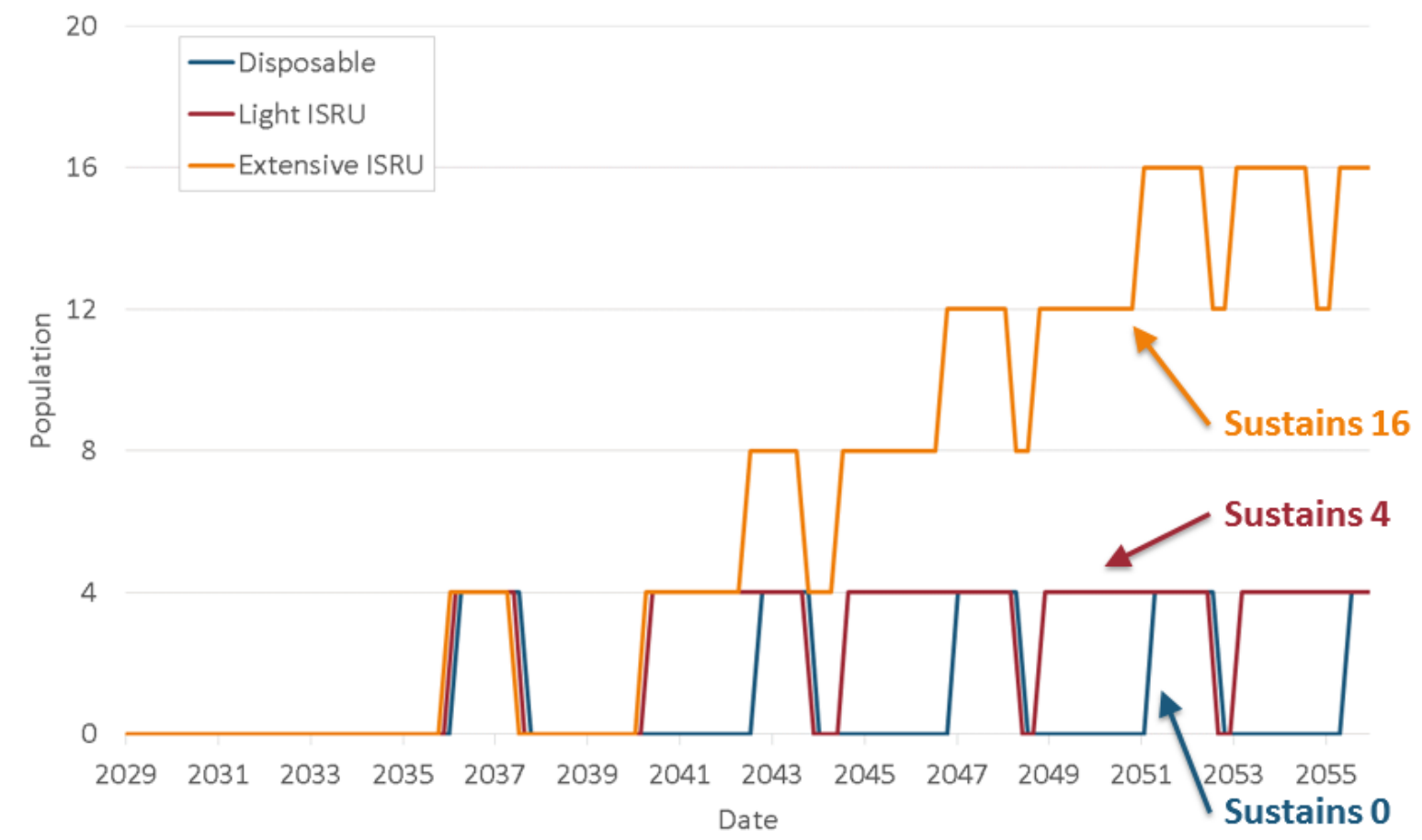

Figure 16: Comparison of Number of Crew on Mars Surface 
The cadence of surface stays is converted to cumulative days on the Martian surface for each campaign, represented in Figure 17. The Disposable Campaign has the lowest cumulative number of crew days by 2055. The Light ISRU Campaign, by having near continuous human presence, has two times that of the Disposable Campaign. The final result of growth to a population of 16 in the Extensive ISRU Campaign is a cumulative number of crew days approximately seven times that of the Disposable campaign, and three times that of the Light ISRU campaign by 2055.

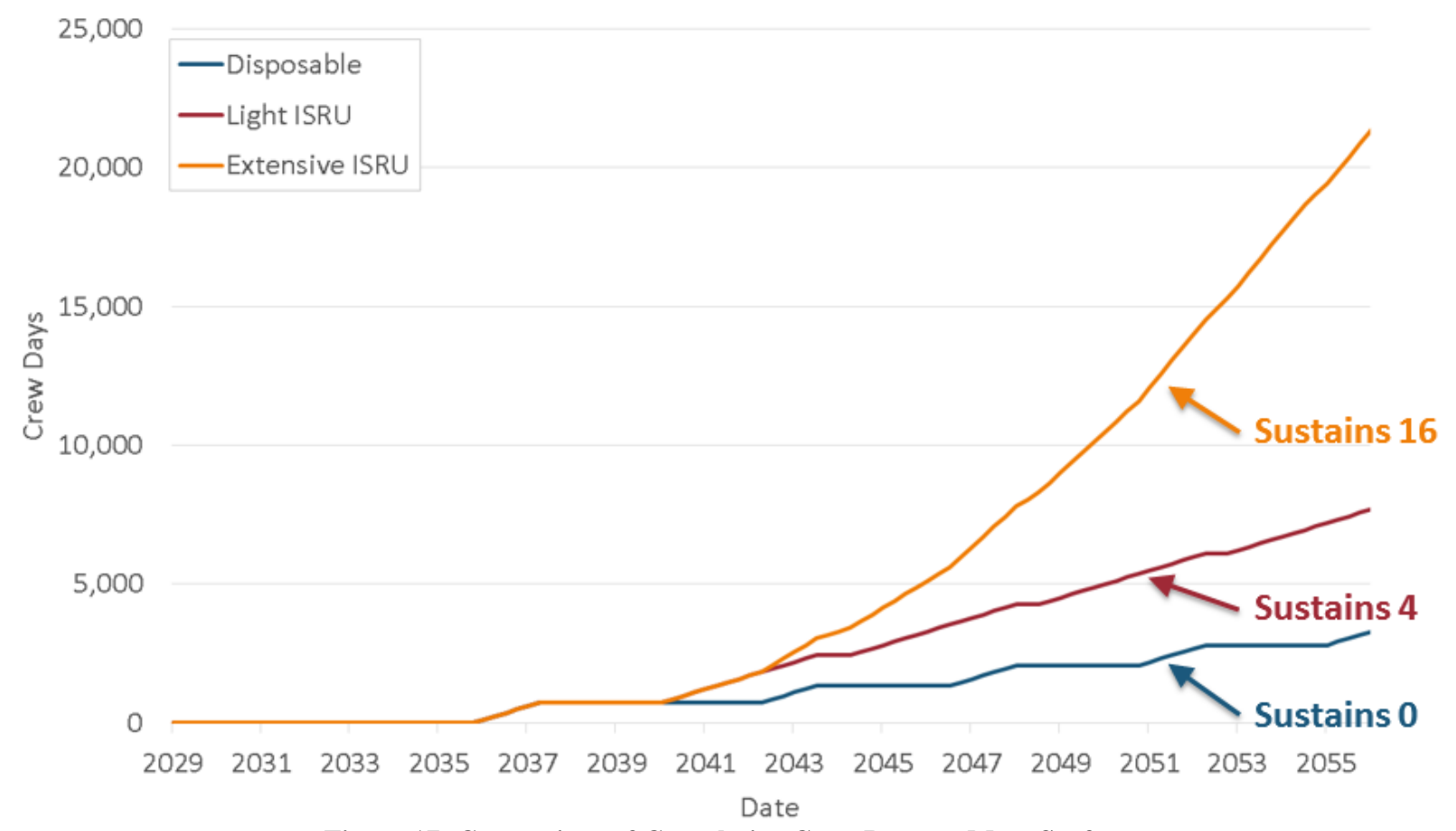

Figure 17: Comparison of Cumulative Crew Days on Mars Surface

With an understanding of the performance of the three campaigns in place, the next consideration is the relative costs. Cost is identified as a key figure of merit and is therefore estimated over the entirety of each of the three campaigns. Cost estimates for individual elements are either obtained from Mars DRA 5.0 [4] or developed using a parametric cost model, the Project Cost Estimating Capability (PCEC), formerly the NASA Air Force Cost Model (NAFCOM). PCEC is NASA's primary parametric cost estimating tool for flight hardware elements and is based on over 155 NASA and Air Force space flight hardware projects. All costs are estimated in 2014 dollars and include Phase A; Design, Development, Testing, and Evaluation (DDT\&E); and production costs (fixed and variable). An additional 30 percent for reserves and 15 percent for program integration is carried on top of these numbers. The cost estimates do not include the following:

- Facilities and facilities maintenance and operations

- Operations capability development

- Operations costs:

$\circ$ Launch operations (fixed and variable)

- Flight/mission operations (fixed and variable)

- Crew Operations

- Research/technology advancement

- Software

The cost versus time results for each of the three campaigns developed for this study are shown in Figure 18. The most noticeable difference between the two ISRU campaigns and the Disposable Campaign is the large additional initial investment associated with developing and producing a reusable lander (Hercules). The higher costs of the Disposable Campaign in the out years is then attributed to the requirement for a new aeroshell, descent vehicle, and 
ascent vehicle (crewed only) for each crew mission to the Mars surface. The increased costs of these disposable elements outweigh the costs of the additional elements associated with the higher population of the two ISRU campaigns. It is interesting to note that once a commitment to develop Hercules is made it is actually a relatively small investment to move from Light ISRU Campaign to Extensive ISRU Campaign. However, this minor investment has a significant pay off in terms of crew days on the surface.

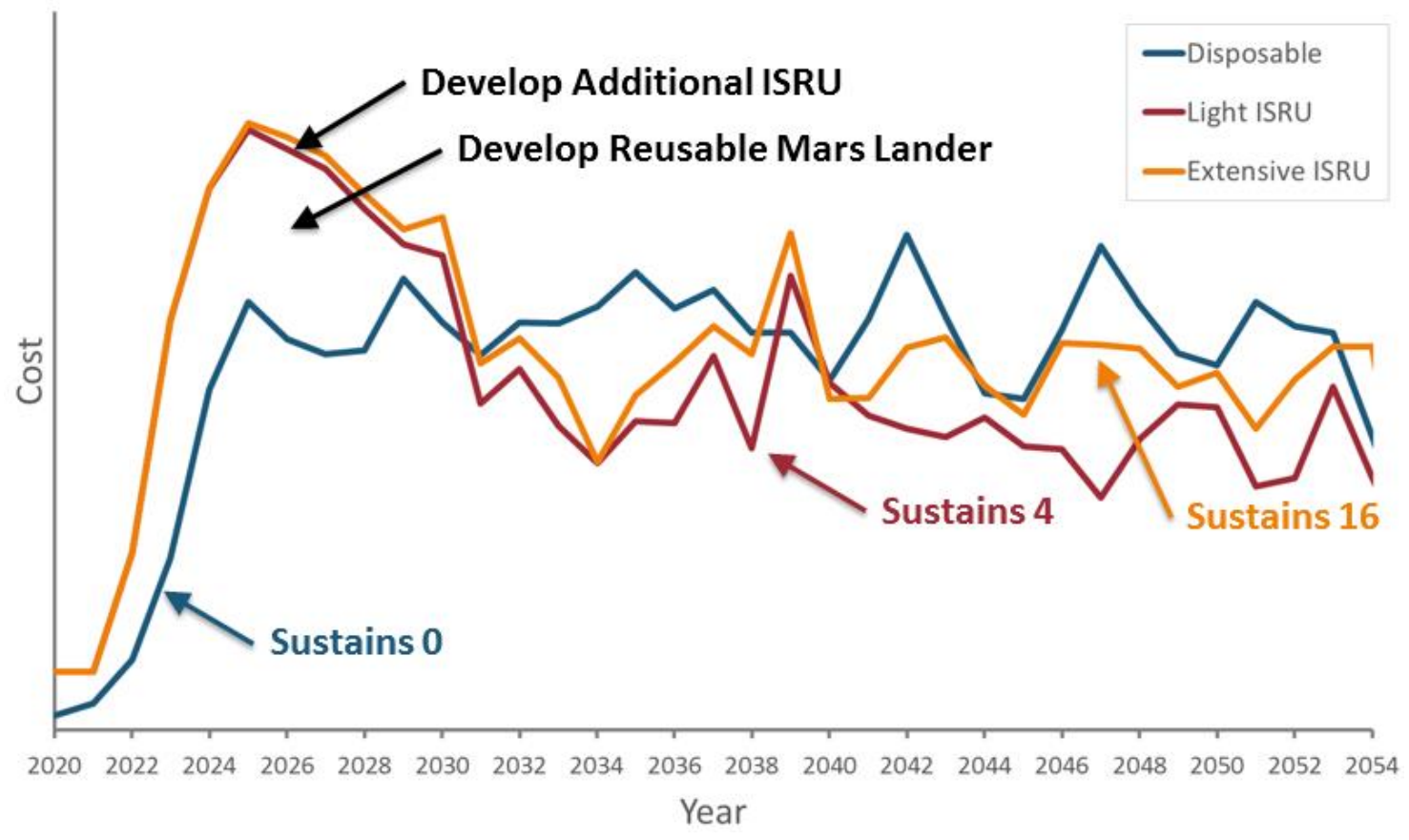

Figure 18: Cost Comparison Over Time for Each Campaign

The cost estimates were used to develop a metric in an attempt to assess the overall merit of the three campaigns. This metric is defined as accumulated cost over accumulated value, represented by crew days on the surface of Mars, and is plotted versus time in Figure 19. Minimizing this metric represents an improved return on investment for the campaign. The first crew on the surface for each campaign occurs in 2036 and therefore, the initial value of accumulated cost over accumulated crew days can be interpreted as the cost to put the first crew on the surface for each campaign. The cost difference between the disposable and ISRU campaigns associated with developing Hercules is displayed on this plot. Also, the extra cost of Extensive ISRU Campaign's ISRU infrastructure relative to Light ISRU Campaign is displayed. The infrastructure investment for the two ISRU campaigns pays off when both campaigns begin near continuous human presence on Mars in approximately 2039. Similarly, the payoff for the Extensive ISRU Campaign relative to Light ISRU Campaign is realized shortly thereafter (around 2042) during the population growth phase.

The key takeaway for comparing the campaigns using this metric is the approach taken to exploring Mars is entirely dependent upon the philosophy of the campaign. If the goal is solely to put boots on Mars for as low cost as possible, the Disposable Campaign is the better choice due to its lower upfront investment. However, with the objective of pioneering, the Extensive ISRU Campaign provides the greatest benefit for the investment. 


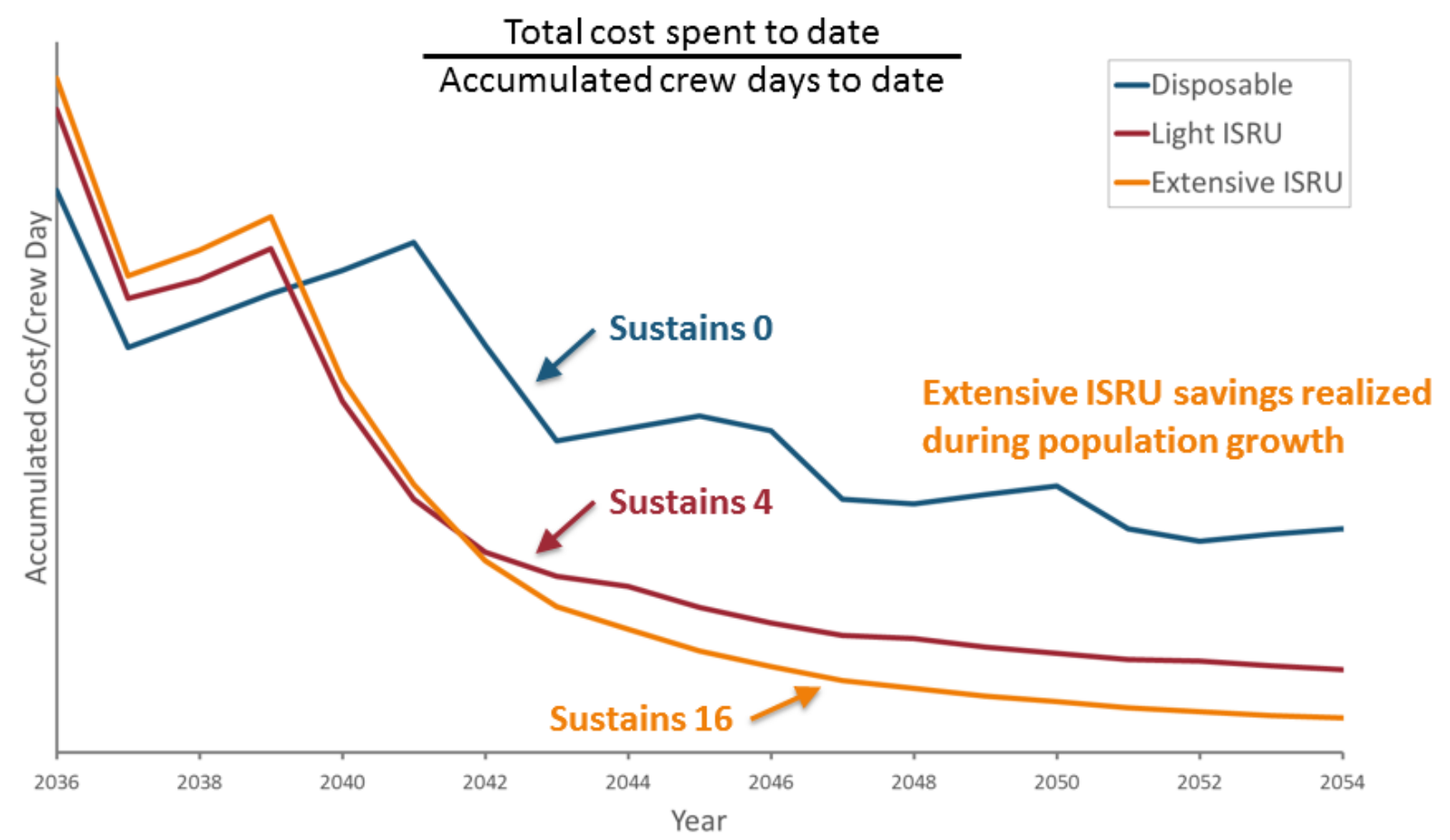

Figure 19: Accumulated Cost per Accumulated Crew Days Over Time

\section{Future Work}

Both the Hercules and Pegasus concept designs require maturation to hone in on optimal solutions, reduce design uncertainties, and establish a more detailed design baseline. To that end, several follow-on efforts are planned or inwork that aim to assess alternative configurations and to mature the design. While a baseline configuration was assumed for Hercules, it does not necessarily represent the best solution nor is it the product of extensive and equitable design trades. As such, efforts are planned to evaluate alternative designs for the overall vehicle configuration and layout. Performance and risk trades are key to understanding the impact on a reusable system. Trades include vehicle configuration, the impact of parking orbit on both the Hercules design and in-space realignment penalties, and the detailed design of the propulsion system. The concepts must also be refined to reduce uncertainty in the concept. Concept maturation assessments include packaging, structural sizing/optimization, mechanical concept definition, aerothermal assessment, propulsion layout, and parking orbit assessment.

The insights that this analysis has provided on the benefit of ISRU, reusability, and automation to enabling a sustained human presence on Mars encourages additional work in the understanding of future campaign planning. The preliminary analysis was performed with low fidelity models, and higher fidelity analysis would provide more confidence in the results. The ISRU models (food, consumables, propellant, etc.) were based on parametric analysis or historical analogues, and bottoms-up design would facilitate a more precise understanding of the system requirements. Alternative campaigns may yield additional insight. For instance, the launch constraint can be removed to analyze the impact on cost and required element performance of an identical crew buildup cadence for all three types of campaigns. This analysis, which assumes high levels of reusability and automation, does not include the impact of element reliability and the mass of spares on transportation and surface systems, including the need for replacing the Hercules as it reaches its lifetime limits. The operations requirements to support these systems from Earth, including communications, are also an important factor that would be included in a future analysis.

\section{Conclusions}

This study analyzed the impact of ISRU, reusability, and automation on pioneering Mars. With current launch assumptions, sustained presence on Mars requires a transition from Earth dependence to Earth independence. The study analyzed the surface and transportation architectures and compared campaigns that revealed the importance of ISRU and reusability. The reusable Mars lander, Hercules, eliminates the need to deliver a new descent and ascent stage with each cargo and crew delivery to Mars, reducing the mass delivered from Earth. As part of an evolvable transportation architecture, this investment is key to enabling continuous human presence on Mars. The extensive use 
of ISRU reduces the logistics supply chain from Earth in order to support population growth at Mars. Reliable and autonomous systems, in conjunction with robotics, are required to enable ISRU architectures as systems must operate and maintain themselves while the crew is not present. In the end, Mars has abundant resources available to support human life, with the extraction and use of in-situ water being the fundamental Martian resource that enables a sustained human presence.

\section{Acknowledgments}

The authors would like to acknowledge the encouragement and support by the Langley Chief Technical Leads, Dennis Bushnell, Walt Engelund, and Keith Belvin. They would also like to acknowledge the support and engineering expertise provided by the Systems Analysis and Concepts Directorate engineers at NASA Langley Research Center.

\section{References}

1. NASA, "Pioneering Space: NASA's Next Steps on the Path to Mars," https://www.nasa.gov/sites/default/files/files/Pioneering-space-final-052914b.pdf, Accessed 6-30-15.

2. Zubrin, R., Daker, D., and Gwynne, O., "Mars Direct: A Simple, Robust, and Cost Effective Architecture for the Space Exploration Initiative," $29^{\text {th }}$ Aerospace Sciences Meeting, AIAA-91-329, Jan. 1991.

3. Rapp, D., Extraterrestrial Resources for Human Space Missions to Moon or Mars, Praxis Publishing, Chichester, UK, 2013.

4. Drake, B., "Human Exploration of Mars Design Reference Architecture 5.0," Tech. Rept. NASA-SP-209566, NASA, 2009.

5. Rapp,D., Human Missions to Mars: Enabling Technologies for Exploring the Red Planet, Praxis, Chichester, UK, 2008.

6. Jones, C., Wilhite, A., Hickman, J., and Wagner, J., "Mars Ascent Vehicle-Optimization of Propulsion with In-Situ Propellant Production," 59 $9^{\text {th }}$ International Astronautical Congress, IAC-08.D1.2.8, Oct. 2008.

7. Portree, D., "Humans to Mars: Fifty Years of Mission Planning, 1950-2000," Tech. Rep. NASA-SP-2001-4521, NASA, Feb. 2001.

8. Reck, G., "Report of the 90-Day Study on Human Exploration of the Moon and Mars," Tech. Rep. NASA-TM-102999, NASA, Nov. 1989.

9. Hoffman, S., and Kaplan, D., "Human Exploration of Mars: The Reference Mission of the NASA Mars Exploration Study Team,” Tech. Rep. NASA-SP-6107, NASA, 1997.

10. Drake, B., "Reference Mission Version 3.0: Addendum to the Human Exploration of Mars: The Reference Mission of the NASA Mars Exploration Study Team," Tech. Rep. SP-6107-ADD, NASA, June 1998.

11. NASA, "NASA's Exploration Systems Architecture Study," Tech. Rep. NASA-TM-2005-214062, NASA, Nov. 2005.

12. Drake, B., "Human Exploration of Mars Design Reference Architecture 5.0: Addendum," Tech. Rep. NASA-SP-2009566-ADD, NASA, July 2009.

13. Mason, L. "Power Technology Options for Nuclear Electric Propulsion." 37 $7^{\text {th }}$ Intersociety Energy Conversion Engineering Conference. IECEC 2002-20159. 2002.

14. Powell, J., Maise, G., Powell, J., and Paniagua, J. "ALPH: A Low Risk, Cost Effective Approach for Establishing Manned Bases and Colonies on Mars.” AIAA SPACE 2005 Conference and Exposition. AIAA-2005-6761. 2005.

15. Carranza, S., Makel, D., and Blizman, B. "In Situ Manufacturing of Plastics and Composites in Support of Human and Robotic Exploration." Space Technologies and Applications International Forum-STAIF 2006. CP813. 2006.

16. Isakowitz, S., Hopkins, J., and Hopkins Jr., J. International Reference Guide to Space Launch Systems, $4^{\text {th }}$ ed. AIAA, 2004.

17. Komar, D.R., Hoffman, J., and Olds, A., "Framework for the Parametric System Modeling of Space Exploration Architectures," AIAA-2008-7845, 2008.

18. Dwyer Cianciolo, A. M., et al., "Entry, Descent and Landing Systems Analysis Study: Phase 1 Report," NASA TTM2010-216720, July 2010.

19. Lopez, P., Schultz, E., Mattfeld, B., Stromgren, C., and Goodliff, K., "Logistics Needs for Potential Deep Space Mission Scenarios Post Asteroid Redirect Crewed Mission,” IEEE Aerospace Conference 2015, Big Sky, MT, March 2015. 